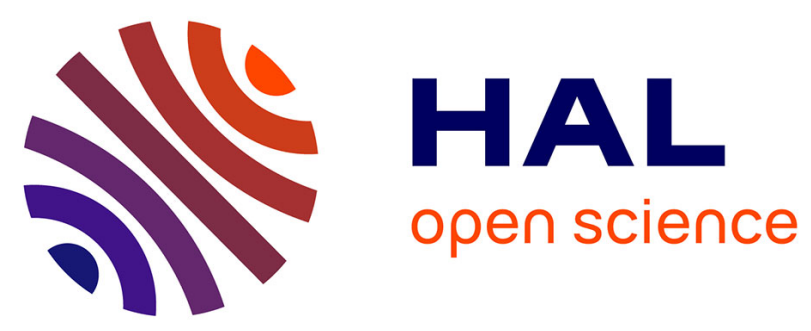

\title{
Tridimensional nonhydrostatic transient rip currents in a wave-resolving model
}

Patrick Marchesiello, Francis Auclair, Laurent Debreu, James C. Mcwilliams, Rafael Almar, Rachid Benshila, Franck Dumas

\section{- To cite this version:}

Patrick Marchesiello, Francis Auclair, Laurent Debreu, James C. Mcwilliams, Rafael Almar, et al.. Tridimensional nonhydrostatic transient rip currents in a wave-resolving model. Ocean Modelling, 2021, 163, pp.101816. 10.1016/j.ocemod.2021.101816 . hal-02883697v3

\section{HAL Id: hal-02883697}

https://hal.inria.fr/hal-02883697v3

Submitted on 29 Mar 2021

HAL is a multi-disciplinary open access archive for the deposit and dissemination of scientific research documents, whether they are published or not. The documents may come from teaching and research institutions in France or abroad, or from public or private research centers.
L'archive ouverte pluridisciplinaire $\mathbf{H A L}$, est destinée au dépôt et à la diffusion de documents scientifiques de niveau recherche, publiés ou non, émanant des établissements d'enseignement et de recherche français ou étrangers, des laboratoires publics ou privés. 


\title{
Tridimensional nonhydrostatic transient rip currents in a wave-resolving model
}

\author{
Patrick Marchesiello ${ }^{\mathrm{a}, *}$, Francis Auclair ${ }^{\mathrm{d}}$, Laurent Debreu ${ }^{\mathrm{e}}$, James McWilliams ${ }^{\mathrm{c}}$, Rafael \\ Almar $^{\mathrm{a}}$, Rachid Benshila ${ }^{\mathrm{b}}$, Franck Dumas ${ }^{\mathrm{f}}$ \\ ${ }^{a} I R D / L E G O S$, Toulouse, France \\ ${ }^{b}$ CNRS/LEGOS, Toulouse, France \\ ${ }^{c}$ University of California, Los Angeles, USA \\ ${ }^{d}$ LA, University of Toulouse, France \\ ${ }^{e}$ Univ. Grenoble Alpes, Inria, CNRS, Grenoble INP, LJK, 38000 Grenoble, France \\ ${ }^{f}$ SHOM, Brest, France
}

\begin{abstract}
Flash rips and surf eddies are transient horizontal structures of the order of 10 to $100 \mathrm{~m}$, which can be generated in the surfzone in the absence of bathymetric irregularities. They are traditionally evaluated in a depth averaged setting which involves intrinsic horizontal shear instabilities and the direct generation of vorticity by short-crested waves. In this article, we revisit the processes of surf eddy generation with a new three-dimensional wave resolution model (CROCO) and provide a plausible demonstration of new 3D non-hydrostatic instability and turbulent cascade. We first present a quick overview of a compressible free surface approach suitable for nearshore dynamics. Its ability to simulate the propagation of surface gravity waves and nearshore wave-driven circulation is validated by two laboratory experiments. Next, we present a real world application from Grand Popo Beach, Benin, forced by waves with frequency and directional spreading. The generation of surf eddies by the 3D model differs from depth-averaged models, due to the vertical shear associated with shallow breaking waves. In this case, the generation of eddies from both horizontal shear instability and the breaking of short-crested waves is hampered, the former by stretching the alongshore current and the latter by inhibiting the inverse energy cascade. Instead, the vertical shear flow is subjected to forced wave group variability and Kelvin-Helmholtz type instability at an inflection point. Primary and secondary instabilities generate spanwise and streamwise vorticity connecting small-scale eddies to larger horizontal surfzone structures. Streamwise
\end{abstract}


filaments, appearing as $5 \mathrm{~m}$ wide ribs or mini-rips, can extend beyond the surfzone but with moderate energy. These results appear consistent with the velocity spectra and observed patterns of tracers and suspended sediments at Grand Popo Beach. The timescale associated with the mean shear-induced turbulence is several times the wave period and suggests an intermediate range between breaker-induced turbulence and large-scale surf eddies. Keywords: Surfzone, Rip currents, 3D instability, Turbulent cascade, Wave-resolving RANS model

\section{Introduction}

Flash rips and surf eddies are generally defined as transient horizontal structures of size 3 ranging between water depth and surfzone width, i.e., of order 10-100 m, which are generated 4 in the surfzone in the absence of bathymetric irregularities. They are studied separately from 5 stationary rip currents confined to deeper channels between sandbars (MacMahan et al., 7 scale with wave height (Cox and Anderson, 2001), and even smaller vortices of the fully s developed turbulent bore (Svendsen and Madsen, 1984). However, the separation between 9 surf eddies and turbulence is uncertain (Longo et al., 2002) and the possibility of intermediate scales and processes linking horizontal and vertical vorticity generation has been suggested 11 - e.g., Short et al. (1993) describing ephemeral and shallow mini rips over Australian low tide terrace beaches — but not clearly demonstrated.

Because it is difficult to sample transient rip currents with sufficient spatial resolution (Lippmann et al., 2016; Henderson et al., 2017), our concepts largely rely on numerical models. Three types of processes stand out:

- Horizontal (2D) shear instability of longshore currents

17

- Short-crested wave vorticity generation (here called Peregrine process)

${ }^{*}$ Corresponding author

Email address: patrick.marchesiello@ird.fr (Patrick Marchesiello) 
- Tridimentional (3D) shear instability

The horizontal shear instability of longshore currents was the earliest process proposed for eddy generation, describing the intrinsic variability of wave-induced currents. Bowen and Holman, 1989; Dodd et al., 1992; Allen et al., 1996; Slinn et al., 1998; Özkan-Haller and Kirby, 1999; Dodd et al., 2000; Uchiyama et al., 2009). This process has generally been studied with wave-averaged shallow water models, in which the momentum transfer from waves to currents is fully parametrized. Its importance has faded over the last decade due to the prevalence of the Peregrine process, but also to the contradictory results given by three-dimensional wave-averaged models. (Newberger and Allen, 2007; Splinter and Slinn, 2003).

The second process, largely due to Peregrine (1998), is the current nearshore community „views of driving mechanisms for wave-averaged circulation in the surfzone (Kirby and Derakhti, 2019). Boussinesq equations for weakly dispersive intermediate and shallow water waves provides a conceptual model for the action of spatially varying wave breaking, i.e., short-crested waves (Johnson and Pattiaratchi, 2006; Bonneton et al., 2010; Feddersen et al., 2011; Clark et al., 2012; Feddersen, 2014). In this model, small vortices result from generation by differential breaking, and combine over time into larger eddies through an inverse cascade mechanism, consistent with 2D turbulence. The surfzone is thus a production center for eddies with scales roughly ranging from 10 to $100 \mathrm{~m}$. In addition, the coastal boundary imposes that eddies and associated filaments can only go offshore, providing a mechanism for enhanced cross-shore dispersion of various tracers.

The theoretical framework from depth-integrated models neglect the effect of vertical shear. Following the advent of robust 3D formulations of wave-averaged equations (McWilliams et al., 2004; Ardhuin et al., 2008), a number of 3D modeling studies have emerged in the last decade (Newberger and Allen, 2007; Uchiyama et al., 2010; Kumar et al., 2012; Marchesiello et al., 2015; Uchiyama et al., 2017; McWilliams et al., 2018; Akan et al. 2020). They show a modulation of nearshore circulation when wave breaking occurs in a shallow surface layer. However, short-crested wave breaking is generally neglected in these 
wave-averaged studies (or addressed in ad-hoc manners) and all real-scale applications to date are performed using hydrostatic assumption, thus underestimating horizontal vorticity motions.

Nonhydrostatic dynamics are essential in our third listed process of surf eddy generation. They are mostly studied in laboratory experiment (Nadaoka et al., 1989) and laboratoryscale Large-Eddy Simulations (LES) using 2.5D CFD models applied to individual wave breaking (Lin and Liu, 1998; Li and Dalrymple, 1998; Watanabe and Saeki, 1999; Watanabe et al., 2005; Lubin and Glockner, 2015). These previous studies show that the spanwise (mostly alongshore) component of vorticity is an important aspect of the breaking process. Surface breaking produces traveling rolls through a primary instability, which can evolve through secondary instability to produce streamwise vorticity, transitioning toward fully tridimensional turbulence.

However, 2.5D CFD models are computationally very expensive and applied to individual breaking waves with only few alongshore wavelengths of the secondary instability, precluding any evaluation of eddy statistics. In addition, these studies do not always clearly distinguish whether the instability is associated with the instantaneous plunging and rebounding jet produced by breakers or with the mean shear flow caused by momentum transfer. Yet, the two processes may be sorted by their timescale, i.e., smaller than the wave period for the rebounding jet (Watanabe et al., 2005) and longer for the mean shear turbulence (Li and Dalrymple, 1998). If confirmed, the latter could therefore be an intermediate phenomenon between breaker-induced turbulence and large-scale surf eddies.

3D nonhydrostatic processes are usually studied independently of the two others (by separate research communities) and rarely compared in terms of scales, magnitude and interaction. The only attempt was made by Splinter and Slinn (2003) in a proceeding report. Using a 3D nonhydrostatic model where breaking acceleration is introduced as a body force, they show that a simulation with deep breaking reproduces $2 \mathrm{D}$ model solutions, while the more realistic shallow breaking process seems to disrupt the formation of horizontal shear instability at the expense of vertical shear instability. However, their domain size does not allow statistical comparisons and the profile of breaking acceleration is imposed, not 
computed from a wave-resolving model. The present study is a step forward compared with this first work, also addressing the case of short-crested wave generation. Note that Kumar and Feddersen (2017) studied transient eddies produced by a 3D nearshore circulation model, forced by short-crested waves computed beforehand with a Boussinesq model. However, wave forcing is prescribed as a depth-uniform body force, i.e., as deep breaking, and could not produce vertical shear of the cross-shore flow. Their hydrostatic assumption also precluded the model from vertical shear instabilities.

CROCO (Coastal and Regional Ocean Community model) is a new oceanic modeling system built upon ROMS (Shchepetkin and McWilliams, 2005, Debreu et al., 2012), with an added non-Boussinesq kernel (Auclair et al., 2018). It solves Reynolds-averaged NavierStokes Equations (RANS) on a free surface and terrain-following grid and is designed to study realistic, fine-scale processes from the regional ocean to the littoral zone. Particular attention is paid to numerical accuracy, high performance computing (optimization, scalability), portability and ease of access ( url www.croco-ocean.org). This paper presents a quick overview of the nonhydrostatic CROCO solver with a non-Boussinesq (compressible) approach, before embarking in its application to nearshore dynamics. First, its ability to simulate the propagation of surface gravity waves, near-shore breaking and the resulting vertical circulation is validated against small and large-scale laboratory experiments. Second, we present a 3D, wave-resolving, real-case simulation of transient rips, in the presence (or not) of short-crested waves and strong alongshore currents. We discuss fundamental differences in the generation of surf eddies by 3D wave-resolving models compared with depth-averaged models, with a focus on the vertical structure of currents produced by shallow breaking and associated turbulence. We conclude on the limitation of simplified vorticity evolution equations in which only the vertical part is considered when so much activity resides in the horizontal vorticity, governed by 3D non-hydrostatic equations.

\section{Model description}

Because of limited computational resources, 3D wave-resolving models are still rarely used to study nearshore dynamics in realistic environments. LES applications appeared in 
the $1990 \mathrm{~s}$ and are generally restricted to 2.5D laboratory-scale experiments of individual wave breaking. Early applications used the volume-of-fluid (VOF) method for free-surface tracking (e.g., Lin and Liu 1998; Watanabe and Saeki 1999; Watanabe et al. 2005; Derakhti and Kirby 2014; Larsen et al. 2020). This model type with Cartesian coordinate, where the free surface crosses computational cells arbitrarily, fails to precisely apply the pressure boundary condition on the free surface, affecting the model accuracy.

More recently, several 3D wave-resolving, free-surface and terrain-following RANS models have emerged for the nearshore zone, e.g., SWASH (Zijlema et al., 2011) and NHWAVE (Ma et al., 2012; Derakhti et al., 2016), based on earlier attempts (e.g., Lin and Li 2002). In this case, the explicit overturning of the free surface is excluded and the breaking wave is modeled instead with a single-valued free surface which follows a shock process and resembles a dissipating bore. Despite the absence of explicit overturning (replaced by parametrized turbulence), these models can be accurate as well as computationally efficient (orders of magnitude cheaper) in the study of waves and wave-driven mean and transient circulation.

CROCO belongs to this class of models but, unlike other attempts, resolves the compressible Navier-Stokes equations (Auclair et al., 2018). A compressible approach preserves the hyperbolic nature of Navier-Stokes equations and does not require a global elliptic solver with incremental pressure corrections to ensure the incompressible mass balance. As a result, it avoids splitting errors between pressure and velocity and approximations made on free-surface conditions (Zijlema et al., 2011; Derakhti et al., 2016), thereby preserving amplitude and nonlinear dispersive properties of surface waves. In the same time, the absence of global computations by an elliptic solver makes parallelization and optimization procedures much more efficient. The cost of solving acoustic waves is managed with a time-splitting technique and semi-implicit time discretization, introduced below.

The development of CROCO around the Regional Oceanic Modeling System (ROMS) has advantages for realistic applications. It benefits from capabilities long developed in oceanic models - high-performance computing; high-order discretization; coupling with biogeochemistry and sediment models; pre-processing tools for rapid generation of model input; various online and offline diagnostics. The nonhydrostatic model version can thus be ap- 
plied without much effort to realistic, highly nonlinear regimes, e.g., large internal solitons and hydraulic jumps (Hilt et al., 2020), Kelvin-Helmholtz instabilities (Penney et al., 2020), Langmuir turbulence (Herman et al. 2020) or wave-induced nearshore circulation as in the present study. It is naturally suited for bridging ocean and coastal sciences, e.g., addressing surf-shelf exchange processes in a 3D, rotating and stratified framework. In addition, both wave-resolving and wave-averaged (Uchiyama et al., 2010; Marchesiello et al., 2015) model equations are available within the same code, which has potential advantages for evaluating the parametrizations of wave-current interactions in wave-averaged models.

\subsection{Free-surface, compressible ocean model equations}

The full set of Navier-Stokes equations for a free-surface ocean is explicitly integrated in the nonhydrostatic, non-Boussinesq (compressible) version of CROCO, built on the code structure of ROMS primitive equation solver. In the compressible approach (Auclair et al., 2018), acoustic waves are solved explicitly to avoid Boussinesq degeneracy, which inevitably leads to a 3D Poisson system in nonhydrostatic incompressible methods - detrimental to computational costs and accuracy of free-surface model implementation.

Non-Boussinesq equations include the momentum and continuity equations, the surface kinematic relation (for free surface), heat, salt or other tracer $C$ conservation equations, and the equation of state, which reads in Cartesian coordinates:

$$
\begin{gathered}
\frac{\partial \rho u}{\partial t}=-\vec{\nabla} \cdot(\rho \overrightarrow{\mathbf{v}} u)+\rho f v-\rho \tilde{f} w-\frac{\partial P}{\partial x}+\mathcal{F}_{u}+\mathcal{D}_{u}+\lambda \frac{\partial \vec{\nabla} \cdot \overrightarrow{\mathbf{v}}}{\partial x} \\
\frac{\partial \rho v}{\partial t}=-\vec{\nabla} \cdot(\rho \overrightarrow{\mathbf{v}} v)-\rho f u-\frac{\partial P}{\partial y}+\mathcal{F}_{v}+\mathcal{D}_{v}+\lambda \frac{\partial \vec{\nabla} \cdot \overrightarrow{\mathbf{v}}}{\partial y} \\
\frac{\partial \rho w}{\partial t}=-\vec{\nabla} \cdot(\rho \overrightarrow{\mathbf{v}} w)+\rho \tilde{f} u-\frac{\partial P}{\partial z}-\rho g+\mathcal{F}_{w}+\mathcal{D}_{w}+\lambda \frac{\partial(\vec{\nabla} \cdot \overrightarrow{\mathbf{v}})}{\partial z} \\
\frac{\partial \rho}{\partial t}=-\vec{\nabla} \cdot(\rho \overrightarrow{\mathbf{v}})
\end{gathered}
$$




$$
\begin{gathered}
\frac{\partial \eta}{\partial t}=\left.w_{f}\right|_{z=\eta}-\left.\overrightarrow{\mathbf{v}}\right|_{z=\eta} \cdot \vec{\nabla} \eta \\
\frac{\partial \rho C}{\partial t}=-\vec{\nabla} \cdot(\rho \overrightarrow{\mathbf{v}} C)+\mathcal{F}_{C}+\mathcal{D}_{C}
\end{gathered}
$$

$(u, v, w)$ are the $(\mathrm{x}, \mathrm{y}, \mathrm{z})$ components of vector velocity $\overrightarrow{\mathbf{v}} ; \eta$ is the free surface; $P$ the total pressure; $\rho$ the density; $f(x, y)$ and $\tilde{f}(x, y)$ are the traditional and non-traditional Coriolis parameters, function of latitude; $g$ is acceleration of gravity; $\mathcal{D}_{u}, \mathcal{D}_{v}, \mathcal{D}_{C}$ are eddy-diffusion terms requiring second-moment turbulence closure models; $\mathcal{F}_{u}, \mathcal{F}_{v}, \mathcal{F}_{C}$ are forcing terms; $\lambda$ is the second (bulk) viscosity, associated with compressibility (used to damp acoustic waves).

\subsection{Time-splitting principle}

In the above set of equations, a relation between $\rho$ and $P$ is required. To that end, and as part of a time-splitting approach, density is decomposed into slow and fast components based on a first-order linear decomposition with respect to total pressure. In the following, $s$ and $f$ subscripts refer to slow and fast-mode components respectively:

$$
\begin{gathered}
\rho=\rho_{s}\left(T, S, P_{s}\right)+\overbrace{\left.\frac{\partial \rho}{\partial P}\right|_{T, S} ^{\rho_{f}=c_{s}^{-2} P_{f}} \delta P}+O\left(\delta P^{2}\right) \\
P=\underbrace{P_{a t m}+\int_{z}^{\eta}\left(\rho_{s}-\rho_{0}\right) g d z^{\prime}}_{S L O W}+\underbrace{\rho_{0} g(\eta-z)+\overbrace{\delta P}^{P_{f}}}_{F A S T}
\end{gathered}
$$

$c_{s}$ is the speed of sound and $\delta P=P_{f}$ is the nonhydrostatic pressure.

The Navier-Stokes equations are then integrated with two different time steps within the time-splitting approach inherited from ROMS. The slow-mode integration is similar to ROMS, with the addition of the slow part of vertical momentum equation, while fastmode integration is in $3 \mathrm{D}$ and includes the compressible terms of momentum and continuity equations. In vector form: 


$$
\begin{gathered}
\frac{\partial \rho \overrightarrow{\mathbf{v}}}{\partial t}=\underbrace{-\vec{\nabla} \cdot(\rho \overrightarrow{\mathbf{v}} \otimes \overrightarrow{\mathbf{v}})-2 \rho \vec{\Omega} \times \overrightarrow{\mathbf{v}}-\vec{\nabla}\left(\int_{z}^{\eta_{f}}\left(\rho_{s}-\rho_{0}\right) g d z^{\prime}\right)+\overrightarrow{\mathcal{F}}_{\overrightarrow{\mathbf{v}}}+\overrightarrow{\mathcal{D}}_{\overrightarrow{\mathbf{v}}}}_{F L O W} \\
\frac{\partial \rho_{f}}{\partial t}=-\frac{\partial \rho_{s}}{\partial t}-\vec{\nabla} \cdot(\rho \overrightarrow{\mathbf{v}}) \\
P_{f}=c_{s}^{2} \rho_{f} \\
\frac{\partial \eta_{f}}{\partial t}=\left.w_{f}\right|_{z=\eta}-\left.\overrightarrow{\mathbf{v}}_{f}\right|_{z=\eta} \cdot \vec{\nabla} \eta_{f} \\
\left.\frac{\partial \rho \eta_{f}}{\partial t}=-\vec{\nabla} P_{f}+\rho_{f} \overrightarrow{\mathbf{g}}+\lambda \vec{\nabla} \cdot \overrightarrow{\mathbf{v}}\right) \\
\rho=\rho_{s}+\rho_{f} \\
\rho_{s}=\rho\left(T_{s}, S_{s}, \eta_{f}\right)
\end{gathered}
$$

The momentum is integrated both in slow and fast modes but the right-hand-side of the equation is split in two parts: a slow part, made of slowly varying terms (advection, Coriolis force, baroclinic pressure force and viscous dissipation), and a fast part, made of fastvarying terms (the surface-induced and compressible pressure force, weight, and dissipation associated with bulk-viscosity). This momentum equation is numerically integrated twice, once with a large time-step keeping the fast part constant, and once with a smaller time-step keeping the slow part constant. This is much more computationally efficient than integrating 
the whole set of equations at the same fast time step. More details can be found in Auclair et al. (2018)1.

Note that acoustic waves can become pseudo-acoustic if their phase speed $c_{s}$ is artificially reduced $\left(c_{s}\right.$ is a model parameter). In this case, high-frequency processes associated with bulk compressibility may be unphysical, but an accurate solution for slower nonhydrostatic dynamics can be preserved, while relaxing CFL constraints. In our nearshore applications, a $c_{s}$ value of $200 \mathrm{~m} / \mathrm{s}$ instead of $1500 \mathrm{~m} / \mathrm{s}$ makes almost no difference for the physical solution but allows a great reduction in the computation time (by almost half).

\subsection{Discretized equations for nearshore applications}

In this study, motions are produced by an offshore wave-maker in a non-rotating, homogeneous fluid. In this case, the Coriolis force, baroclinic pressure force and all surface fluxes are null. There is no temperature or salinity stratification so that slow density $\rho_{s}$ is constant in time and space.

CROCO is discretized on a C-grid with finite-difference methods for slow and fast modes that are detailed elsewhere (Shchepetkin and McWilliams, 2005; Soufflet et al., 2016). In short, the slow-mode time-stepping algorithm is a Leapfrog Adams-Moulton predictorcorrector scheme, that is third-order accurate for integrating advective terms. The fast mode is integrated with a generalized forward-backward scheme, which is also third-order accurate. Vertical flux terms that do not require accuracy (vertical diffusion term in the slow mode and all acoustic terms of $w$ equation in the fast mode) are computed with an implicit time stepping to increase computational stability.

Horizontal and vertical advection terms are discretized using the WENO5-Z improved version of the 5th-order weighted essentially non-oscillatory scheme (Borges et al., 2008), which is popular for hyperbolic problems containing both shocks and smooth structures.

\footnotetext{
1 Auclair et al. (2018) presented a first implementation of the compressible approach involving a 3-level time splitting (internal, external and acoustic). CROCO was simplified to only retain a slow and a fast time level, where acoustic waves are solved together with the external (depth-averaged) mode. This procedure is more computationally efficient
} 
WENO5-Z naturally copes with dispersive numerical modes as well as shocks caused by breaking waves, with no need for ad hoc criteria.

\subsection{Turbulence closure}

Along with the numerical treatment of breaking waves, a $k-\epsilon$ or $k-\omega$ model, solving the closure equations for turbulent kinetic energy $k$ and dissipation $\epsilon$ or dissipation rate $\omega \propto \epsilon k^{-1}$, is used as part of a Generic Length Scale (GLS) method (Warner et al., 2005). In the absence of buoyancy forcing, the turbulence equations express a balance between transport, diffusion, shear production and dissipation:

$$
\frac{\partial \rho k}{\partial t}=-\vec{\nabla} \cdot(\rho \overrightarrow{\mathbf{v}} k)+\mathcal{D}_{k}+\rho(P-\epsilon)
$$

$$
\frac{\partial \rho \epsilon}{\partial t}=-\vec{\nabla} \cdot(\rho \overrightarrow{\mathbf{v}} \epsilon)+\mathcal{D}_{\epsilon}+\rho \frac{\epsilon}{k}\left(c_{\epsilon 1} P-c_{\epsilon 2} \epsilon\right)
$$

or

$$
\frac{\partial \rho \omega}{\partial t}=-\vec{\nabla} \cdot(\rho \overrightarrow{\mathbf{v}} \omega)+\mathcal{D}_{\omega}+\rho \frac{\omega}{k}\left(c_{\omega 1} P-c_{\omega 2} \epsilon\right)
$$

The eddy viscosity $\nu_{t}=c_{\mu} l k^{\frac{1}{2}}$ is derived from these equations, with coefficient $c_{\mu}$ dependent on stability functions, and mixing length $l \propto k^{\frac{3}{2}} \epsilon^{-1} . l$ is resolution independent, which is consistent with a RANS rather than LES approach. The shear production term for $k$ is $P=2 \nu_{t} S_{i j} S_{i j}$, with the mean strain rate tensor $S_{i j}=\frac{1}{2}\left(\frac{\partial u_{i}}{\partial x_{j}}+\frac{\partial u_{j}}{\partial x_{i}}\right)$ (using Einstein notation). All turbulence model parameters are given in Warner et al. (2005), based on Burchard et al. (1998) for $k-\epsilon$ and Wilcox (1988) for $k-\omega$. The only present modification in the $k-\epsilon$ model concerns the surface mixing length (a model boundary condition), which is briefly discussed in the validation section 3.2 . For this reason, and for its robustness through resolutions and benchmarks, the $k$ - $\omega$ model will be our standard turbulence model. However, we note as Mayer and Madsen (2000) and Larsen and Fuhrman $(2018)$ that this model tends to produce excessive mixing in potential flow regions, i.e., on the innershelf. This problem will be addressed in further studies, including realistic conditions of stratification and wind forcing. 


\subsection{Wave maker at offshore boundary}

The wave maker forces a spectrum of $3 \mathrm{D}$ linear waves at the offshore boundary, as in

Zijlema et al. (2011), rather than as an interior source term (Wei et al., 1999). The spectrum has frequency and directional spreading similar to Feddersen et al. (2011):

$$
\eta_{b c}(y, t)=\sum_{i} a_{i} \sum_{j} d_{j} \cos \left(k_{y, i j} y-\omega_{i} t-\phi_{i j}\right)
$$

$$
\text { with } d_{j}=\mathrm{e}^{-\left(\frac{\theta_{j}-\theta_{m}}{\sigma_{\theta}}\right)^{2}} \text { and } \sum d_{j}=1
$$

4

$$
u_{b c}(y, t)=\eta_{b c}(y, t) \omega_{p} \cos \left(\theta_{m}\right) \frac{\cosh \left(k_{p}(z+h)\right)}{\sinh \left(k_{p} h\right)}
$$

$$
v_{b c}(y, t)=\eta_{b c}(y, t) \omega_{p} \sin \left(\theta_{m}\right) \frac{\cosh \left(k_{p}(z+h)\right)}{\sinh \left(k_{p} h\right)}
$$

where $(\mathrm{x}, \mathrm{y}, \mathrm{z})$ are cross-shore, alongshore and vertical directions respectively; $(i, j)$ are indices of spectral distribution in frequency and direction respectively; $a_{i}$ is the amplitude at each frequency $\omega_{i}$, from a given statistical distribution, e.g., JONSWAP (Sec. 4.1); $k_{y, i j}=k_{i} \sin \left(\theta_{j}\right)$ is the alongshore wavenumber, where $k_{i}$ is the linear theory wavenumber: $\omega_{i}^{2}=g k_{i} \tanh \left(k_{i} h\right)$ with $h$ the mean water depth; $\theta_{j}$ is wave angle, $\theta_{m}$ is the mean wave direction and $\sigma_{\theta}$ the directional spread around the mean; $\omega_{p}$ and $k_{p}$ are peak frequency and wavenumber; $d_{j}$ is a normalized frequency-dependent directional distribution; $\phi_{i j}$ is a uniformly distributed random phase.

Here $w_{b c}$ is set to zero and our tests show only weak sensitivity to this choice. Depthaveraged (barotropic) velocities $(\bar{u}, \bar{v})$ must be provided as well in the wave maker because they are prognostic variables of our split-explicit model, advanced together with the fast acoustic mode. Normal depth-averaged velocity $\bar{u}$ is complemented at the boundary by an anti-Stokes "compensation flow", opposite to Stokes drift and thus closing the volume budget. We do not impose the depth-averaged value of $u_{b c}$ directly but the value of the incoming characteristic of the shallow water system as in Flather-type conditions (Marchesiello et al. 
2001; Blayo and Debreu, 2005):

$$
\bar{u}=\bar{u}_{b c}-\sqrt{\frac{g}{h}}\left(\eta-\eta_{b c}\right)
$$

This allows infragravity waves generated inside the domain to propagate out as long waves, while ensuring a near conservation of mass and energy through the open boundary. Likewise, the baroclinic components $\left(u_{b c}, v_{b c}, w_{b c}\right)$ are applied via an adaptive radiation condition which helps short waves and 3D flow perturbations to leave the domain with only a small effect on the interior solution (Marchesiello et al., 2001).

\section{Validation in Flume experiments}

\subsection{GLOBEX experiment}

As a first step towards 3D modeling, we present here a validation of wave propagation and breaking using a wave flume experiment. The Gently sLOping Beach EXperiments (GLOBEX ${ }^{2}$ ) were performed in the Scheldt flume of Deltares (Delft, the Netherlands) in 2012, and described in Michallet et al. (2014). The project objective was to collect highresolution space-time data of the cross-shore evolution of short and infragravity waves on a gentle slope for a range of wave conditions.

The flume is $110 \mathrm{~m}$ long, $1 \mathrm{~m}$ wide and $1.2 \mathrm{~m}$ high. The waves were generated with a piston-type wave maker equipped to minimize reflections from the wave paddle. A concrete beach with a weakly reflexive 1:80 slope was constructed, with its toe at $16.57 \mathrm{~m}$ from the wave maker. All experiments were run with a still water depth of $0.85 \mathrm{~m}$ and shoreline at $x=84.57 \mathrm{~m}$. The material that was laying loose on the concrete bed before the flume was filled with water had a median grain size D50=0.75 mm.

Sea-surface elevation measurements were taken at 190 locations (repeating an experiment ten times while relocating the 21 wave gauges), together with velocity measurements at 43 locations, mostly (but not always) at $1 \mathrm{~cm}$ above bed to focus on the undertow. The sampling frequency of the instruments during these experiments is $128 \mathrm{~Hz}$. Here, we focus

\footnotetext{
${ }^{2}$ Globex data is freely available at zenodo.org/record/4009405
} 
on experiment B3, corresponding to second-order (Stokes) wave generation of bichromatic frequencies (simulated with a Boussinesq model in Michallet et al.|2014). The characteristics are as follows: $a_{1}=0.09 \mathrm{~m} ; a_{2}=0.01 \mathrm{~m} ; f_{1}=0.420 \mathrm{~Hz} ; f_{2}=0.462 \mathrm{~Hz}$ (short-wave peak period $T_{p}=2 /\left(f_{1}+f_{2}\right)=2.27 \mathrm{~s} ;$ and group period $\left.T_{g}=1 /\left(f_{2}-f_{1}\right)=23.81 \mathrm{~s}\right)$. The signal had a total duration of 75 minutes.

The model is set-up with the same conditions as the wave flume experiment. Secondorder bichromatic waves are generated at the offshore boundary, with shore normal direction and zero directional spread. A no-slip condition is imposed on the lateral wall boundaries of the canal so that transverse modes are precluded. The grid spacing is $d x=1 \mathrm{~cm}$ with 10 vertical levels evenly spaced between the free surface and bottom. A simulation with 20 levels gave similar results, while the solution is moderately degraded (mostly in higher moments) with coarser horizontal resolution $(d x=3,6$ and $12 \mathrm{~cm})$, which shows good convergence properties. The model time step is $d t=0.15 \mathrm{~ms}$. The minimum depth is $1 \mathrm{~mm}$ on the shore, the position of which varies with the swash oscillation, relying on a wetting-drying scheme (Warner et al., 2013). For bottom drag, the logarithmic law of the wall is used with roughness length $z_{0} \sim D 50 / 12=0.0625 \mathrm{~mm}$.

Figure 1 compares an Hovmuller plot (x,time) of data and model sea level $\eta$ and undertow $u_{b} . u_{b}$ is interpolated at the measurement depth When some data is missing in the measurements, it is also removed from the model output. The general structure reflecting wave speed and frequencies, wave packets, surf and swash zones are all very similar. Modeldata correlations are high with 0.85 and 0.80 respectively for $\eta$ and $u_{b}$, and root mean square errors are $2.7 \mathrm{~cm}$ and $12.2 \mathrm{~cm} / \mathrm{s}$. Some scattering in the undertow data is noticeable. According to Michallet et al. (2014), it may be attributed to the presence of secondary motions generated by transverse waves at the break point where the transverse mode- 1 seiche can be excited at frequency $f_{1}+f_{2}$. It may also be due to variations in the depth level of flow measurements.

A snapshot of wave field across the flume during runup (Figure 2) highlights the main processes of propagation, nonlinear wave-wave interactions, shoaling, breaking, roller propagation and runup. Model-data correlation is high, as already mentioned, and non-linearity 
is apparent in both cases in the increasingly non-sinusoidal shape of short waves as they approach the shore (Elgar and Guza, 1985). They first develop short, high wave crests with increasing skewness (asymmetry about the horizontal axis, measuring crest/trough shape), and as they break, transition into the characteristic saw-tooth shape with asymmetry about the vertical axis.

Wave statistics (first, second and third moments) for $\eta$ and $u_{b}$ are shown in Figure 3 ; mean, standard deviation (or $H_{s}$ for $\eta$ ), skewness $\left\langle{\phi^{\prime}}^{3}\right\rangle /\left\langle{\phi^{\prime}}^{2}\right\rangle^{1.5}$ and asymmetry $\left\langle\mathcal{H}\left(\phi^{\prime}\right)^{3}\right\rangle /\left\langle{\phi^{\prime}}^{2}\right\rangle^{1.5}$ ( $\mathcal{H}$ is Hilbert transform). The model sea-level statistics (left of Fig. 3) closely resemble the measurement data, including high-order moments, showing the transition from skewness to asymmetry across the shoaling and surf zones (with two peaks in the asymmetry profile corresponding to outer and inner surf zone evolution).

For the mean field of measured undertow, a few scattered points lying far outside the standard deviation are corrected using a polynomial fit. The model appears to replicate the observed cross-shore undertow profile (top-right of Fig. 3). The undertow is part of a vertical recirculation associated with breaking-induced surface onshore flow. Here, we call undertow the bottom return flow $(10 \mathrm{~cm} / \mathrm{s}$ in this experiment), which includes the Eulerian anti-Stokes compensation flow (preserving Lagrangian flow continuity). The latter is the only undertow component captured by depth-averaged models and is relatively weak (on the order of $1 \mathrm{~cm} / \mathrm{s}$ in this simulation). In Figure 3, the model also correctly represents high-order moments, which show profiles similar to those of the sea level (skewness and asymmetry).

From sensitivity tests, it appears that a realistic reproduction of $H_{s}$ cross-shore evolution in the surfzone benefits from using a shock capturing scheme (WENO5-Z). The results are degraded (not shown) when replacing WENO5-Z with UP5, a non-monotonic linear upstream-biased 5th-order advection scheme (Menesguen et al., 2018). This is in line with analogies between breaking waves, bores and hydraulic jumps, that may be treated as a shock (Cienfuegos et al., 2010; Tissier et al., 2012; Lubin and Chanson, 2017). The preservation of steep wave fronts by shock-capturing schemes can help generate asymmetry, even to the excess depending on resolution (Tissier et al. 2012). However, this is balanced here by 
additional eddy viscosity from the turbulence model, which is otherwise required (below wave trough level) to capture the right vertical shear, as shown next.

\subsection{Large-scale LIP flume experiment}

The undertow may be considered as a proxy for vertical shear, which will appear as an essential parameter of surf eddy generation in the next section. To further confirm the model's ability to simulate this shear, we now present a comparison with the European Large Installation Plan (LIP) experiments, designed for profile validation and carried out at full scale in Delft Hydraulics's Delta Flume (Roelvink and Reniers, 1995). It will also be a test for our numerical wave maker in its ability to generate a spectrum of random waves.

The Flume is $225 \mathrm{~m}$ long, $5 \mathrm{~m}$ wide and $7 \mathrm{~m}$ deep. In LIP, three types of experiments were designed with different wave conditions, which subsequently resulted in a stable (A), erosive (B), and accretive (C) beach state. Here, we use the erosive experiment (LIP11D-1B). The wave conditions were a JONSWAP narrow-banded random wave spectrum generated by a wave paddle, with characteristics $H_{s}=1.4 \mathrm{~m}, T_{p}=5 \mathrm{~s}$, and peak enhancement factor $\gamma=3.3$. Under this wave forcing, a sandbar formed and slowly migrated across the initial beach profile of slope 1:30, consisting of a median grain size of $0.22 \mathrm{~mm}\left(z_{0} \sim D 50 / 12=0.02\right.$ $\mathrm{mm}$ ). A movable carriage was placed $10 \mathrm{~cm}$ above the bed to capture the depth-varying structure of the currents at 10 locations along the flume with a given accuracy of $2 \mathrm{~cm} / \mathrm{s}$. We use measurements taken after 8 hours in experiment $1 \mathrm{~B}$ and averaged over one hour.

The model setup is adapted from the GLOBEX experiment to the LIP experiment. In particular, a JONSWAP wave spectrum similar to the experiment is generated with shore normal direction and zero directional spread. The grid spacing is $d x=25 \mathrm{~cm}$ with 10 vertical levels evenly spaced between the free surface and bottom. Here again, a simulation with 20 levels gave similar results and a test of coarser horizontal resolutions $(d x=50 \mathrm{~cm}$ and $1 \mathrm{~m})$ is presented below. The model time step is $d t=25 \mathrm{~ms}$.

Figure 4 shows a comparison of the model with data, using our standard configuration. The match with measured currents is very good throughout the complex morphology of the beach. The waves start to break before the sandbar, but the breaking is more intense on 
the sandbar, where the surf is strongest on the onshore side. The resulting undertow has a strong shear and maximum intensity of about $30 \mathrm{~cm} / \mathrm{s}$. The resolution test $(25 \mathrm{~cm}, 50 \mathrm{~cm}$ and $1 \mathrm{~m}$ ) shows a mean error of about $3 \mathrm{~cm} / \mathrm{s}$ at all resolution, close to the measurement error of $2 \mathrm{~cm} / \mathrm{s}$. The results are thus consistent at all resolution despite no adjustment of any parameter. With the small-scale GLOBEX experiment, it confirms the validity of a RANS approach for estimating the mixing length of breaking-induced turbulence — which will be distinguished from mean shear-induced turbulence in the next section.

Turbulent kinetic energy and eddy viscosity estimated by the $k-\omega$ model in the breaker zone have the expected structure (Fig. 4; top) and magnitude $\left(\nu_{t} \sim 0.01 h \sqrt{g h}\right.$; Svendsen 1987; Cox et al. 1994). Interestingly, the transport terms in the closure equations tend to reduce mixing at break point by redistributing the turbulent energy, thus allowing a more intense shear to be maintained (not shown). The $k-\epsilon$ model works almost as well as the $k-\omega$ model, with respect to mean current profiles, but the comparison is improved by imposing a high value on the surface mixing length $(0.2 \mathrm{~m})$, as in wave-averaged models (Feddersen and Trowbridge, 2005; Kumar et al., 2012)). The $k-\omega$ model may thus be a better choice for surface wave breaking, possibly due to a more accurate near wall treatment (Mayer and Madsen, 2000; Devolder et al., 2018; Larsen et al., 2020). Note, however, that this model produces a greater amount of mixing in potential flow regions outside the surf zone (innershelf), mainly due to the divergence part of the mean strain rate tensor Mayer and Madsen (2000).

While an extensive study of surfzone turbulence is beyond the scope of this paper, we conclude that our combination of numerical and physical closures with off-the-box parameters, although perfectible, provides a realistic and robust framework for the horizontal and vertical circulation in the surfzone.

\section{Natural beach application}

We now turn to a full 3D experiment with longshore-uniform bathymetry. The configuration is derived from Grand Popo Beach $\left(6.2^{\circ} \mathrm{N}, 1.7^{\circ} \mathrm{E}\right.$, Benin, in the Gulf of Guinea; Fig. 5). This stretch of coast presents a longshore-uniform, low tide terrace and steep upper 
shoreface (Almar et al., 2014, 2016) and a sandy wave-dominated and microtidal environment, exposed to S-SW long period swells generated at high latitudes in the South Atlantic (Almar et al., 2015a). A field experiment was conducted at Grand Popo Beach from 10 to 18 March 2014 (Almar et al. 2014; Derian and Almar, 2017). For our setup, we focus on conditions in the middle of the afternoon of March 13 2014. The weather, tides and wave conditions were ideal: weak winds and wind waves well separated from a narrow-band swell with significant wave height $H_{s}=1.15 \mathrm{~m}$, peak period $T p=11 \mathrm{~s}$, and wave incidence $D=10^{\circ}$ from shore normal direction (measured from an Acoustic Doppler Current Profiler moored in 10-m depth). The water was at mid neap tide level (low-tide terrace at about $1 \mathrm{~m}$ depth), promoting a narrow surfzone less than $50 \mathrm{~m}$ wide. A Nortek high-frequency acoustic Doppler velocimeter (ADV with sampling rate of $8 \mathrm{~Hz}$ ) was deployed in the surfzone, in the middle of the terrace, measuring currents about $0.5 \mathrm{~m}$ from the bottom. A dye release was conducted to monitor the dispersion induced by flash rips, coupled with UAV flights (STB DS6 hexacopter) at an elevation of $100 \mathrm{~m}$. The Drone camera (NIKON D700) was looking down, with a vertical angle, and recorded 4256×2832-px scenes at $1 \mathrm{~Hz}$ (Almar et al., 2014, Derian and Almar, 2017).

\subsection{Model Setup}

The domain is $542 \mathrm{~m}$ alongshore by $240 \mathrm{~m}$ across-shore, with periodic alongshore boundary conditions. In order to prevent distortion when oblique waves are used with periodic conditions, the alongshore size is adjusted according to peak wavelength and mean wave direction. This method proved to perform well even with long-crested waves. The grid spacing is $d x=d y=0.5 \mathrm{~m}$. There are 10 vertical levels evenly spaced between the free surface and bottom (a simulation with 20 levels did not change the results much). The model time step is $d t=0.01 \mathrm{~s}$. The bathymetry is longshore-uniform and built with continuous functions to smoothly fit the low-tide terrace structure observed during the survey of (Almar et al., 2014, 2018). The depth $h$ is $8 \mathrm{~m}$ offshore to $1 \mathrm{~mm}$ at shore level, the position of which varies with the swash oscillation (wetting-drying scheme of Warner et al. 2013). The depth on the terrace is about $1 \mathrm{~m}$, which corresponds to the mid-tide conditions of the afternoon 
of March 13, 2014.

The wave maker is set with following parameters: $H_{s}=1.15 \mathrm{~m}, T p=11 \mathrm{~s}, D=0^{\circ}, 10^{\circ}$, and directional spread $\sigma_{\theta}=30^{\circ}$. A JONSWAP spectrum is constructed with these parameters and a peak enhancement factor $\gamma$ of 3.3. The WENO5-Z scheme is used again with the $k-\omega$ turbulence model. Bottom roughness is $z_{0}=0.01 \mathrm{~mm}$, which may seem low but gives a drag coefficient $C_{D} \sim 0.002$ in the surfzone $\left(C_{D}=\left(\kappa / \log \frac{z_{1}}{z_{0}}\right)^{2}\right.$, with $\kappa=0.41$ and $z_{1} \sim H / 10$ the first level height above bed), a usual value in depth-averaged models (Chen et al., 2003, Feddersen et al., 2011). We follow the practice of these models here to reproduce their results within the pseudo-2D approach described below. It is of little consequence for 3D simulations because, as will be shown, they are much less sensitive to bottom drag than 2D models (Sec. 5). The model is run for an hour starting from rest and adjusting through a rapid spin-up phase. Figure 6 presents a snapshot of sea level that shows realistic features: short-crested waves generated at an angle, refract and break, producing rollers, swash and some reflection.

CROCO comes with capabilities for water quality, marine ecosystem and sediment modeling. In the present study, they are used with simple settings. First, we introduce a passive tracer in the swash zone for comparison with dye releases made during the beach survey. Second, a suspended sediment model (Blaas et al., 2007; Warner et al., 2008) allows the rip patterns to be compared with aerial photos taken during the survey. We use a single fine sand class with settling velocity of $1 \mathrm{~cm} / \mathrm{s}$. For resuspension, taking one sediment bed layer for simplicity, only two parameters are needed: critical shear stress and erosion rate at the seafloor, expressed in the erosion flux (Blaas et al., 2007):

$$
E=E_{0}(1-p) \frac{\tau_{b}-\tau_{c r}}{\tau_{c r}} \text { for } \tau_{b}>\tau_{c r}
$$

$\tau_{b}$ is the bottom shear stress computed by the model. $E_{0}$ is an empirical erosion rate set to $10^{-5} \mathrm{~kg} / \mathrm{m}^{2} / \mathrm{s} ; p$ is the sediment porosity $(0.41) ; \tau_{c r}$ is the critical shear stress, i.e., the threshold for initiation of sediment motion, set to $0.01 \mathrm{~N} / \mathrm{m}^{2}$. 


\subsection{Shallow vs. deep breaking (and a Boussinesq model)}

The Peregrine vorticity generation process only requires short crested waves, with no need for unstable longshore currents generated by oblique waves. Boussinesq models are very efficient in this process, but an important question for us is whether a 3D model will remain so. An essential difference between the two types of model is the depth penetration of wave breaking. In a 2D Boussinesq model, deep breaking is implicitly assumed as momentum is transferred instantaneously to the depth-averaged flow. However, this is a rough assumption as the breaking-induced flow is produced essentially above trough level (where the onshore flow is located), while turbulence generated at the surface spreads downward by diffusion with a limited mixing length of 10 to 30 percent of the water depth (Svendsen, 1987; Cox et al., 1994; Mocke, 2001; Longo et al., 2002). (Uchiyama et al., 2010) show that the deep breaking assumption is inconsistent with the cross-shore velocity profiles measured during Duck94. Splinter and Slinn (2003) also suggest that transient dynamics produced by deep breaking may collapse in the more realistic case of shallow breaking. The results presented here are in agreement with these studies and we propose to assess the role of 3D dynamics on surf eddies by comparing simulations forced by shallow and deep breaking. Deep breaking will constitute a pseudo-2D model whose results can be compared with a Boussinesq model solution (Section 4.5).

Boussinesq-type models (see Barthelemy 2004, for a review) are common tools to simulate weakly dispersive waves and their transformations from the ocean to the swash zone. Several developments allowed their application to a wide range of scales, from surfzone processes to ocean basin-scale tsunami propagation (Kirby, 2016). Here, for a verification of our pseudo2D CROCO version, we use FUNWAVE-TVD (Shi et al., 2012). It solves the fully nonlinear Boussinesq equations using a hybrid finite-volume finite-difference scheme. Parametrizations are similar to CROCO, with wave breaking handled by a shock capturing TVD scheme (making the need of explicit criterion unnecessary) and a quadratic drag formulation with $C d=0.002$ for bottom friction. Note that newer generation models than FUNWAVE are available with better dispersive properties - using Green-Naghdi equations (Lannes and Bonneton, 2009) or incorporating an additional enstrophy equation (Kazakova and Richard, 
2019) - but FUNWAVE is widely used and share with this class of models the essential depth-averaged assumption.

To force deep breaking in a 3D wave-resolving model, we can artificially enforce strong, deep vertical mixing around the breaker zone by multiplying the vertical eddy viscosity by 10 (from values of $\nu_{t} \sim 0.01-0.05 \mathrm{~m}^{2} / \mathrm{s}$ ). Figure 7 shows a time and longshore average of cross-shore and alongshore currents in the case of shallow and deep breaking. Shallow breaking is computed by the 3D model with no explicit constrain on penetration scale (but a parametrization of eddy viscosity induced by breakers and currents). It drives a shallow onshore flow about $40 \mathrm{~cm}$ deep and an offshore near-bottom undertow, resulting in strong vertical shear of about $1 \mathrm{~s}^{-1}$. With artificially strong vertical viscosity, momentum in the breaker zone is almost instantly mixed to the bottom and the cross-shore flow is reduced to the part required by mass-conservation (the anti-Stokes compensation flow), and consistent with depth-averaged models. The longshore flow driven by oblique waves and a number of other simulations with shallow and deep breaking (Tab. 2) will be analyzed and compared in the following sections.

\subsection{Reference simulations and comparison with data}

To introduce the 3D processes of flash rip generation, we present simulations with shallow and deep breaking (3D_SC_D10 and 2D_SC_D10), representing mid-tides conditions on March 132014 in Grand Popo Beach. Figure 8 compares the vertical vorticity of surface flow: $\omega_{z}=\frac{\partial v_{s}}{\partial x}-\frac{\partial u_{s}}{\partial y}$, phase-averaged over two peak periods $(22 \mathrm{~s}$ ). With deep breaking (left panel), the vortical field is rich with large filaments and surf eddies of 50-100 m scale that are generated from short-crested waves, similar to Boussinesq model solutions. However, the full 3D model with shallow breaking offers a radically new solution (Fig. 8, right panel). Some of the large-scale fluctuations are present but over-shadowed by shorter scales. This mode presents itself as rib structures (or mini rips following a relevant observation by Short et al. 1993, already mentioned) with short longshore wavelength of about $5 \mathrm{~m}$ and period about 1 min.

We now compare the two simulations with data collected during the survey of March 


\footnotetext{
${ }^{3}$ During the survey, a few attempts of dye release were made before obtaining a clear filament patch. Similarly for the model, we selected one occurrence among few tracer patches initialized at regular interval along the coast (in the swash zone). Even though all tracer patches eventually ended up with similar Vshape and similar scales of evolution, there was variability in the evolution and we selected the most visually comparable filament with Drone photos.
} 
shore advection. With deep breaking, advection is weak and the longshore flow remains centered in the breaker zone (Fig. 7). This is a common bias of depth-averaged models (Larson et al., 2002).

Another qualitative comparison of patterns can be made, looking at surfzone suspended sediments in the aerial photo (Fig. 11, left panel). The contrasts in the photo is enhanced to better expose suspended sediments (brown color), which is seen weakly extending beyond the surfzone. Snapshots of the model's surface sediment concentration is also shown after 15 min of simulation. With shallow breaking (center panel), sediments tend to resuspend in the breaker zone and mix efficiently within the surf zone, but only weakly extend to the innershelf. The rib structure is apparent at the seaward front of sediment concentration. It is also apparent in white streaks representing alongshore surface current convergence, that have a structure similar to the foam lines in the aerial photo. Overall, the patterns are similar to the observations, particularly in the upper part of the photo, where there is less foam or sunglint. The same suspended sediment simulation with deep breaking gives very different results (Fig. 11, right panel). Resuspension is now maximum in the inner surfzone (as for eddy energy; Sec. 4.5). Filaments and eddies are more coherent, larger, their growth slower, but extend further seaward. Mixing in the surfzone is less efficient than for the shallow-breaking case, but shelf-surf exchange is more intense, due to filament extension.

For a more quantitative local comparison, we now turn to ADV measurements of horizontal velocities $u_{h}=\sqrt{u^{2}+v^{2}}$. Figure 12 presents the Power Spectral Density (PSD) of velocity fluctuations, using Welch's noise reduction method, for the model and ADV data in the middle of the terrace (left panel) and for the model alone over the outer terrace slope (right panel). The short-wave spectrum around the peak period (11 s) is well represented given the JONSWAP approximation made for the model wave maker. At a lower frequency, a good fit with the data is also given by the full 3D solution, while the deep-breaking simulation exhibits two opposite biases in successive frequency ranges (valid at $95 \%$ confidence level), which are even more pronounced near the terrace slope. These biases are consistent with those noted in Feddersen et al. (2011). The first is an underestimation of energy by the pseudo-2D model in the 30-100s period range. This band is consistent with visual in- 
spection of rip structure oscillation in animated vorticity fields. The 3D model seems to correct the deficit, particularly in the lower frequencies. Note that this energy range for 3D eddies overlaps that of infragravity waves, making it difficult to separate the two phenomena from observations alone. At very low frequency (VLF), for timescales between 2 and $15 \mathrm{~min}$, a second bias of opposite sign is observed in the pseudo-2D model solution. In this range, the eddies produced by short-crested waves have more energy in the deep-breaking case than in the 3D case, as predicted by inspection of vorticity and suspended sediment. The comparison with the data therefore suggests that the VLF energy is overestimated by depth-averaged models, consistent with Feddersen et al. (2011) and Newberger and Allen (2007).

We conclude from this section that the observations at Grand Popo Beach are in better agreement with a complete 3D solution of surf eddies that includes the presence of $3 \mathrm{D}$ rib structures. Next, we analyze their generation process.

\subsection{Structure and production of vertical shear instability}

The surfzone eddy variability seen in the $3 \mathrm{D}$ model solution is truly three-dimensional. Vertical vorticity is only one manifestation, but horizontal vorticity is the main player. Figure 13 presents the Q field defined by $Q=-\frac{1}{2} \frac{\partial u_{i}}{\partial x_{j}} \frac{\partial u_{j}}{\partial x_{i}}$, using Einstein summation convention over the three dimensions. $\mathrm{Q}$ is commonly used to enhance detection of vortical flows. Here, we split cross-shore and alongshore Q components $\left(Q_{y}=-\frac{\partial u}{\partial z} \frac{\partial w}{\partial x}-\frac{1}{2} \frac{\partial u}{\partial x}^{2}\right.$ in red and $Q_{x}=-\frac{\partial v}{\partial z} \frac{\partial w}{\partial y}-\frac{1}{2} \frac{\partial v}{\partial y}$ in green), then normalize them and only plot positive isosurface values 0.02 for clarity (negative values give counter-rotating features).

The result is strikingly consistent with instabilities of a transitional mixing layer (Metcalfe et al., 1987; Lesieur, 1990), the transition being constrained by surfzone width. $Q_{y}$ shows spanwise "rolls" created from the primary instability while $Q_{x}$ identify streamwise "ribs" that are transverse (counter-rotating) vortices from secondary instability (assumingly growing from perturbations generated between the rolls, in the braid region). Note that streamwise designate the shear direction, which is cross-shore, rather than the oblique wave direction. The reason is that the bottom flow aligns with the surface flow in the alongshore 
direction, forming only a weak mean vertical shear (Fig. 7). However, the rips can take an oblique direction when advected by the mean longshore flow. They extend seaward beyond the surfzone while stretching in the vertical direction. Filaments of vertical vorticity (or $Q_{z}$, not shown) also have similar rib structures to $Q_{x}$, recognisable in the surface vorticity plot of Figure 8 ,

The mean shear flow is composed of the wave-mean surface onshore flow and associated seaward undertow (Fig. 7). The inflected velocity profile is inviscidly unstable to small perturbations and unstable modes of Kelvin-Helmholtz type can emerge. The spanwise rolls are large vertical eddies that rapidly evolve into transverse (streamwise) rib vortices connected by "braid" regions, and stretched seaward and downward. This picture is reminiscent of descriptions based on measurements and simulations at the laboratory scale (Nadaoka et al. 1989; Watanabe et al., 2005; Lubin and Glockner, 2015) but, here, the instabilities are generated by the wave-mean shear flow rather than by direct breaking - breaking-induced turbulence is parametrized. It is therefore more consistent with the instability of the undertow profile described by Li and Dalrymple (1998).

According to linear stability analyses, the wavelength of primary shear instability setting the distance between spanwise rolls is an order of magnitude larger than the mixing layer width $\delta$ - in free shear layers (Michalke, 1964, 1965), wavelength, frequency and growth rate of the most unstable modes are $14 \delta, 0.015 U / \delta$ and $0.1 U / \delta$ respectively. The secondary instability wavelength is of the same order as that of the primary instability $(2 / 3$ in Pierrehumbert and Widnall 1982). If the mixing layer width is taken as the vorticity thickness $\delta=\Delta U /\left[\frac{\partial u}{\partial z}\right]_{\max } \sim 50 \mathrm{~cm}$, then the wavelength of both roll and rib structures is about $5 \mathrm{~m}$, consistent with our simulation. Note that given an effective resolution of 5-10 $d x$ for CROCO (Soufflet et al., 2016), a grid resolution of $0.5 \mathrm{~m}$ can be considered "eddy resolving" for 3D instabilities under current conditions. As for frequency, the mixing layer size would be associated with modes around $0.015 \mathrm{~Hz}$ (60 s period), a range usually reserved to surf beat. The model with 3D instability has energy in this range that is lacking in the deep breaking case (see previous section and Fig. 12), but we will see that nonlinear interactions can spread this energy around the injection scale (Sec. 4.6). Note that the 
ribs sometimes develop localized pairing, which may be evidence of subharmonic resonance, another instability associated with shear layers (Craik, 1971; Pierrehumbert and Widnall, 1982; Herbert, 1983).

In order to isolate the mechanism of eddy-mean flow interaction, we analyze a solution forced with monochromatic, shore-normal, long-crested waves (3D_MONO_D0 in Tab. 2). This simulation has constant wave forcing in both space and time when averaging over the wave period $(11 \mathrm{~s})$. In this case, the same rib structure is generated (Fig. 14) but without the large-scale alongshore variation seen in the full solution (Fig. 8, right panel). A comparison of this simulation with other test cases will be presented in the next section. Here, we analyse the mechanism and patterns of shear production. The EKE source terms $-\overline{u_{i}^{\prime} u_{j}^{\prime}} \frac{\partial \bar{u}_{i}}{\partial x_{j}}$ represent the energy spent by the mean flow to feed the instability leading to rolls and ribs. The largest of these terms is the vertical shear production $-\overline{u^{\prime} w^{\prime}} \frac{\partial \bar{u}}{\partial z}$ (Metcalfe et al. 1987), which is shown in Fig. 15. There is a lesser contribution from cross-shore convergence $-\overline{u^{\prime} u^{\prime}} \frac{\partial \bar{u}}{\partial x}$ (all other 7 combinations are negligible). The main site of shear production is in the breaker zone (Fig. 15) and the maximum values are located at the inflection point in the mean velocity profile (represented by a magenta line), in agreement with mixing layer instability theory. The figure also shows a cross-section of mean eddy kinetic energy $\left(E K E=\frac{1}{2}\left(u^{\prime 2}+v^{\prime 2}+w^{\prime 2}\right)\right.$, where $u^{\prime}, v^{\prime}, w^{\prime}$ are fluctuations of phase-averaged velocities, with respect to the time-mean flow presented in Fig. 7). EKE and shear production have a similar spatial pattern, although high EKE values extend from the production center in all directions. The primary rolls are thus produced in the outer surfzone but turbulent energy is diffused by the mean and eddy flow across the water depth and towards both the inner surfzone and innershelf. EKE transport is stronger at the surface and streamwise filaments extend farther offshore at the surface than at the bottom (despite some amount of vertical stretching as they leave the terrace).

For comparison, the mean subgrid-scale turbulent kinetic energy (TKE) produced by the $k-\omega$ closure equations is also shown in Figure 15 (bottom). EKE and TKE have a similar structure, while EKE amplitude is about a quarter of that of TKE. The mean shear turbulence intensity is thus a significant part of total 3D turbulence generated by breaking 
waves. We expect that part of TKE (parametrized by the closure model) could be transferred to EKE if a higher resolution was used.

\subsection{Short-crested waves and the Peregrine process}

An important question of our study concerns the effect of wave variations (frequency and directional spreading) on flash rip generation in a full 3D model. To address this question, it is useful to simplify the problem and progressively add the multiple conditions of variability. In this section, we analyse shore-normal, short-crested wave simulations with shallow or deep breaking (3D_SC_D0 or 2D_SC_D0). Shore-normal conditions prevents the formation of a longshore current and associated horizontal shear instability. In addition, we look at longcrested wave solutions to isolate the effect of 3D instabilities, i.e., the monochromatic solution (3D_MONO_D0), presented in the previous section, and a similar case with JONSWAP frequency spectrum (3D_LC_D0). This latter comparison will help evaluate the effect of frequency spreading on eddy variability before addressing the effect of directional spreading.

Figure 16 compares vertical vorticity for shore-normal, short-crested wave cases. As for oblique waves, deep-breaking leads to a rich vortical field with large filaments extending far offshore, similarly to Boussinesq models. This is confirmed here with a comparison between FUNWAVE-TVD and pseudo-2D CROCO applied to the same configuration. A difference between Boussinesq and pseudo-2D solutions is the effect of 3D dynamics over the innershelf in the latter case, where surface-intensified offshore eddies and filaments present a more fragmented aspect due to a forward energy cascade (Uchiyama et al., 2017; McWilliams et al., 2018). However, the full 3D nonhydrostatic model with shallow breaking (Fig. 16. right panel) shows again different patterns from both Boussinesq and pseudo-2D solutions with regular rib structures having a shorter alongshore scale and a more limited cross-shore extension. Figure 17 presents EKE cross-sections for all shore-normal wave experiments. A striking element of these figures is the presence of large surface and bottom EKE in the shallow breaking cases. This pattern is not a result of shear production because it is absent from the monochromatic case (see previous section and Fig. 15). Therefore, it can only result from wave groups associated with frequency spreading. Through wave height modulation, 
wave groups produce variability in the surface onshore flow and associated undertow. The variability amounts to about half the integrated mean EKE. However, it is much smaller in the deep-breaking case, consistent with depth-averaged model results (de Schipper et al. 2014).

We now turn to the effect of directional spreading. In Figure 17, short-crested waves (produced by directional spreading) extend EKE production over a wider surf zone than longcrested waves, were EKE is confined to the breaker zone. However, the seaward extension is significantly larger in the pseudo-2D model, confirming the impression made from vorticity inspection. Further confirmation is given by vertical EKE integration (and normalization by mean depth; Fig. 18). It highlights 3 distinct regions: the inner and outer surfzone and innershelf. The top panel presents unfiltered data. In this case, 3D instability and wave group forcing dominates eddy production in the surfzone. The deep-breaking solution has a larger cross-shore expansion, extending out to the innershelf, where EKE levels are twice as high as in the shallow breaking case. This is even clearer using a low-pass filter on velocity fluctuations, removing a large part of variability from 3D instability and wave group forcing (bottom panel of Fig. 18). What remains is closer to the usual definition of surfzone eddies as Very Low Frequency features. There is now a maximum in the inner surfzone, consistent with findings from previous Boussinesq model studies that filaments forced by short-crested waves originate in the inner surfzone, then spread offshore, forming eddies that grow in scale (Johnson and Pattiaratchi, 2006). However, the difference of EKE profiles between deep and shallow breaking cases is reminiscent of the overestimation of shelf-surf exchange by Boussinesq models (see profiles of dye concentration in Fig. 10 of Hally-Rosendahl and

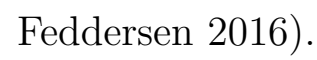

\section{6. $2 D$ and 3D surfzone turbulent cascade}

If there is energy produced by short-crested waves in the inner surfzone of the shallow breaking case, the question is why does it produce fewer large filaments than the deep breaking case. We found an answer in computing the spectrum energy flux. In 2D turbulence, the flux of energy is negative and small fluctuations can grow into larger coherent structures. 
This process is usually involved to explain the growth of filaments and eddies from variable wave forcing (e.g., Johnson and Pattiaratchi 2006; Feddersen 2014). An inverse cascade in the surfzone has recently been confirmed by observations (Elgar and Raubenheimer, 2020), but how efficient is it exactly?

To answer this question, we performed a wavenumber spectral flux analysis for pseudo2D and 3D simulations 2D_SC_D0 and 3D_SC_D0 (Fig. 19). The spectral flux is computed as in Marchesiello et al. (2011) by spectral integration of $v$ advection term. Consistently with $2 \mathrm{D}$ turbulence there is a strong inverse cascade of kinetic energy (negative flux) in the pseudo-2D model starting from the scale of injection corresponding to short-crested wave forcing (wavelength of $\sim 30 \mathrm{~m}$ here), and there is no direct cascade towards smaller scales. In the 3D case, the turbulent regime is different. The negative flux of energy produced by variable wave forcing is present but signifcantly reduced. In addition, there is a second injection at smaller scales that corresponds to the most unstable mode of 3D instability (wavelength of about $5 \mathrm{~m}$ ). This small-scale energy travels both backward and forward across the spectrum and thus widens the range of variability associated with 3D instability. In the 3D long-crested wave case 3D_LC_D0, a similar spectral flux is produced at small scales but there is no large-scale inverse cascade due to missing injection by short-crested waves.

This analysis confirms that the growth of filaments and eddies associated with the Peregrine process heavily relies on a $2 \mathrm{D}$ inverse cascade, but this cascade is impaired by $3 \mathrm{D}$ dynamics. In this case, vorticity fluctuations generated by waves with finite alongshore extent produce less coherent horizontal structures than in the 2D paradigm built on depthaveraged models (Johnson and Pattiaratchi, 2006). The extent of this inhibition process depends on the intensity of turbulent mixing. Sensitivity analysis using reduced viscosity shows that lower viscosity leads to a reduction of the $2 \mathrm{D}$ inverse cascade at VLF, but to an increase of energy production and fluxes at smaller scales. The opposite is true when increasing viscosity. Therefore, breaking waves can transfer energy into both 2D and 3D transient circulations but the distribution of energy between the two regimes is regulated by turbulent mixing which occurs at a higher frequency. These regimes are not mutually 
exclusive, at least within some range of turbulence intensity, the realism of which still needs to be better evaluated.

\subsection{Oblique waves and horizontal shear instability}

The precedent experiments with shore-normal waves show that shallow breaking tends to hinder the generation of large 2D eddies by short-crested waves, while sustaining forced and intrinsic 3D surfzone eddy dynamics. We now address the case of oblique waves with direction $D=10^{\circ}$. From linear stability analysis of a 2D problem (Bowen and Holman, 1989), the wavelength, frequency and growth rate of the most unstable shear waves are $\lambda_{h}=2.5 \mathrm{~L}$ and $f_{h}=0.07 \frac{\mathrm{V}}{L}, \sigma_{h}=0.15 \frac{\mathrm{V}}{\mathrm{L}}$ where $V$ is the longshore current magnitude and $L$ is the longshore current half-width (outer shear). For a narrow, shoreline-intensified jet typical of Grand Popo at mid-tide (Almar et al., 2014, 2015b), shear can be strong $\left(\sim 0.05 \mathrm{~s}^{-1}\right)$, implying a minimum shear wave period of $5 \mathrm{~min}$, wavelength of $80 \mathrm{~m}$, and growth time $\sigma_{h}^{-1}=3 \mathrm{~min}$.

When forcing long-crested waves $\left(\sigma_{\theta}=0\right)$ with deep breaking (2D_LC_D10), CROCO recovers results that are typical of wave-averaged shallow-water models (or 3D models with deep breaking as in Kumar and Feddersen 2017). Figure 20 (left panel) shows an active horizontal shear instability producing shear waves with wavelength consistent with the linear theory. Shear waves propagate with the longshore current as they become nonlinearly unstable, generating filaments and eddies that extend offshore. When both horizontal shear instability and short-crested wave vorticity generation are active (with deep breaking), eddies and filaments are more prominent (3rd panel of Fig. 20). However, with shallow breaking, the horizontal shear instability appears weaker and is again replaced by rib structures. Both horizontal processes are thus reduced by the vertical shear.

Inspection of the cross-shore profile of mean longshore currents (Fig. 7) may help to understand how shallow breaking undermines horizontal shear instability. With deep breaking, cross-shore advection is inactive and the longshore current remains trapped over the terrace slope (which is steep in Grand Popo, around 1/10), and its outer shear is strong. With shallow breaking, however, the longshore current is advected by the cross-shore circu- 
lation, stretching its profile across the terrace so as to minimizes the outer shear. Then, the instability growth rate becomes too weak to overcome friction (from turbulence or bottom drag). This may explain, for example, the puzzled observation by Newberger and Allen (2007) that their 3D wave-averaged model produced no horizontal shear instability, unlike many previous 2D modeling studies (Allen et al., 1996; Slinn et al., 1998; Uchiyama et al., 2009).

This inhibitory process is verified in Figure 21, showing cross-shore profiles of the mean and eddy flow averaged over time and the alongshore direction for the four cases of oblique waves. Horizontal shear instability is best assessed with the term for horizontal shear production of turbulent kinetic energy: $-\overline{u^{\prime} v^{\prime}} \frac{\partial \bar{v}}{\partial x}$. In all cases, the shear production is clearly correlated with the outer and inner slopes of the mean longshore current, with higher production in the outer shear. Deep-breaking cases show higher shear production and greater EKE centered on the outer slope of the terrace, where the shear is greatest. In the case of horizontal shear instability alone (2D_LC_D10), the magnitude is lower than that of 2D_SC_D10, despite similar shear intensity. This indicates an amplification of shear instability by short crested waves as they drive transient intensification of longshore currents. In this case also, The EKE maximum extends farther offshore than expected from shear production, possibly due to mean and eddy advection, but short-crested waves provide the most efficient process for innershelf eddy activity.

The shallow-breaking cases (3D_LC_D10 and 3D_SC_D10) also features horizontal shear production, but weaker and in shallower water, where friction is more prevalent. As a result, EKE is significantly reduced. Short-crested waves (3D_SC_D10) appear to amplify the inner surfzone energy (compared with 3D_LC_D10), but in both cases the offshore energy is considerably reduced.

\section{Discussion and conclusion}

Flash rips and surfzone eddies are traditionally conceived within a depth-averaged framework that involves intrinsic horizontal shear instabilities or/and direct short-crested wave 
vorticity generation. They are revisited in this study using a 3D nonhydrostatic waveresolving model applied to a natural beach with ideal longshore-uniform topography (Grand Popo Beach, Benin). We first presented a quick overview of a new free-surface, compressible approach adapted to wave-resolved nearshore dynamics. Its ability to simulate surface gravity wave propagation, nearshore breaking and the resulting circulation is validated against small- and large-scale laboratory experiments. Then, the model is applied to the neashore circulation generated at Grand Popo Beach by waves with frequency and directional spreading. We assume on the basis of the comparison with Boussinesq solutions that the essential difference between 2D and 3D models is reduced to the vertical profile of breaking-induced acceleration, i.e., deep or shallow breaking. This allows a direct comparison of 2D and 3D frameworks within the same model equations and setup.

The generation of transient rips by the 3D model is shown to differ from that produced by depth-averaged models, owing to the vertical structure of currents produced by surfaceintensified acceleration. Processes of both horizontal shear instability and short-crested wave breaking are limited in our 3D model by the cross-shore vertical recirculation, which can restrict an otherwise strong inverse cascade. Variable wave forcing (in space and time) tends to increase flow variability in the surfzone (especially at the surface and bottom), but it does not fully translate into large-scale rips streaming far offshore. Usual 2D mechanisms may thus be weaker than expected but complemented by a Kelvin-Helmholtz-type instability generated at the inflection point of the mean vertical shear flow. The latter generates rib structures with spanwise and streamwise (alongshore and cross-shore) vorticity of intermediate scale between turbulence and large horizontal eddies — timescale several times the wave period encroaching on the infragravity wave range and wavelength around $5 \mathrm{~m}$. Streamwise filaments extend beyond the surfzone but with lower intensity than usual VLF rips (the offshore mean EKE can be halved). Comforted by observed energy spectra and patterns of tracer and sediment concentrations at Grand Popo Beach, our study may call into question the accuracy of nearshore depth-averaged models. It may explain, in particular, the evidence of overestimation by these models of the shelf-surf exchange (Spydell and Feddersen, 2009, Hally-Rosendahl and Feddersen, 2016) or VLF variability (Feddersen et al., 2011). 
Our results are representative of mid-tide conditions of a low tide terrace with moderate wave heights. Interestingly, the rib structures that are described here are comparable to the mini rips described for similar conditions by Short et al. (1993): Under typical midtide conditions, with waves breaking across the bar, a low 'friendly' surf zone is produced. Waves are less than $1 \mathrm{~m}$ and most water appears to head toward the shore. In fact it is return seaward also, both by reflection of the beach face and via the mini rips, even if no rip channel are present. The rips, however, are usually weak, ephemeral and shallow.

In order to assess the ubiquity of mini rips in the nearshore zone, future $3 \mathrm{D}$ studies should explore different nearshore conditions. Several sensitivity tests were performed in this study, which we only briefly report, pending further exploration of the model parameter space in the future. Nevertheless, they provide useful material for discussion. We first tested the effect of wave amplitude as it affects the breaking-induced flow and turbulence. A simulation forced with twice as large waves $\left(H_{s}\right.$ from 1.15 to $\left.2.30 \mathrm{~m}\right)$ did not fundamentally change the results. In case of higher waves, breaking-induced turbulence can reach deeper depths but the cross-shore flow acceleration is also stronger, so the result on vertical shear is uncertain. Next, we tested a different beach profile, from the steep slope of Grand Popo to a more gentle slope (smaller Iribarren number) similar to Duck Beach (as in Noyes et al. 2005). Here again, the results were similar, as the intensity of the mean vertical shear does not appear to be too sensitive to the beach slope. The bottom roughness length $z_{0}$ was another relevant parameter. As $z_{0}$ is increased from 0.01 to $1 \mathrm{~mm}$, the drag coefficient goes from about 0.002 to 0.008 . Simulations with deep breaking were very sensitive to these values and the largest roughness value can completely shutdown horizontal shear instability due to shorter frictional time (decreased from 5 to 2 min, i.e., shorter than growth time of about $3 \mathrm{~min}$ ), and also damp vortical generation by short-crested waves. On the contrary, full 3D solutions with shallow breaking are only weakly sensitive to bottom roughness, because of surface intensified currents and shorter growth time of 3D instability. These tests inspire greater confidence in our results, while highlighting the overestimated importance given to bottom drag in studies using depth-averaged models (e.g., Allen et al. 1996).

Eddy viscosity provides the largest source of sensitivity in our results. Artificially chang- 
ing the eddy viscosity coefficient lead to qualitatively similar results but with significant variation in the intensity of processes. An increase of eddy viscosity in the surfzone reduces the vertical shear, damps vertical shear instability - as the frictional time $h^{2} / \nu_{t}$ becomes closer to the growth time of about 1 minute — and intensifies the inverse turbulent cascade. In the same time, cross-shore advection is reduced so that the wave-averaged longshore flow is sharper and in deeper waters, therefore more sensitive to horizontal shear instability. Therefore, there is a relationship between the intensity of turbulence and sorting of energy that enters 2D and 3D dynamical regimes. Given the present model uncertainty, we can only infer that these regimes are not mutually exclusive and should coexist. More validation in different settings will be needed to assess their relative importance.

Finally, the present modeling study shed light on the mechanistic process that could inhibit the generation of surf eddies by short-crested waves. Vertical vorticity generation by the Peregrine process can be written as:

$$
\frac{\partial \omega_{z}}{\partial t}=-\frac{\partial F_{b r}}{\partial y_{c}}
$$

where $F_{b r}$ is the breaking force, extending to the bottom in a depth-averaged model, and $y_{c}$ is the along-crest direction. Using a parametrization for breaker acceleration, Clark et al. (2012) propose a scaling relation for vorticity generation of a single wave as $H_{s}^{3} h^{-2.5}$, at a maximum in the outer surfzone. However, flash rip generation originates in the inner surfzone in depth-averaged models (Johnson and Pattiaratchi, 2006) as well as in our simulations. Therefore, a transient vorticity source in the outer surfzone is not sufficient to generate the expected local horizontal recirculation (with offshore filament). It needs a coastal boundary and an inverse energy cascade that transform vorticity fluctuations into larger-scale coherent structures, as shown by our spectral flux analysis. In a 3D regime, this cascade can be reduced (due to vortex tilting by the shear flow; McWilliams et al. 2018) and the variability generated in the inner surfzone does not fully translate into large rips jetting offshore.

In conclusion, our results suggest that nearshore dynamics and transport processes may be affected by nonhydrostatic dynamics, not only for surface gravity waves and small-scale turbulence as is well known, but also for larger-scale vortical motions. We expect this 
conclusion to be qualitatively valid in other applications, but further studies should explore the range of parameters encountered in the global coastal ocean. Most importantly, they should pay special attention to how these parameters affect the mean cross-shore current profiles as a key to 3D transient dynamics.

\section{Acknowledgement}

This research has received support from a consortium of French research agencies, as part of CROCO's development project (GdR CROCO). It was granted access to the HPC resources of CALMIP supercomputing center under allocation P19069. The fieldwork received support by the French INSU/EC2CO program (Grand Popo Experiment). We thank H. Michallet for sharing the GLOBEX data, now freely available at zenodo.org/ record/4009405, and Dano Roelvink for sharing the LIP data. Apart from these, all data were acquired by the authors and the CROCO source code is freely available at www.croco-ocean.org. Both observational and modeling data are available upon request.

\section{References}

Akan, C., McWilliams, J.C., Uchiyama, Y., 2020. Topographic and coastline influences on surf eddies. Ocean Modelling 147, 101565.

Allen, J.S., Newberger, P.A., Holman, R.A., 1996. Nonlinear shear instabilities of alongshore currents on plane beaches. Journal of Fluid Mechanics 310, 181-213.

Almar, R., Almeida, P., Blenkinsopp, C., Catalan, P., 2016. Surf-swash interactions on a low-tide terraced beach. Journal of Coastal Research 75, 348-352.

Almar, R., Du Penhoat, Y., Honkonnou, N., Castelle, B., Laibi, R., Anthony, E.J., Sénéchal, N., Degbe, G., Chuchla, R., Sohou, Z., Dorel, M., Mensah-Senoo, T., Quenum, M., Addo K., A., Ibaceta, R., Kestenare, E., Zodehougan, G., Laryea W., S., Lefebvre, J., 2014. The Grand Popo experiment, Benin. Journal of Coastal Research SI 70, pp. 651-656.

Almar, R., Kestenare, E., Reyns, J., Jouanno, J., Anthony, E., Laibi, R., Hemer, M., Du Penhoat, Y., R., R., 2015a. Response of the bight of benin (gulf of guinea, west africa) coastline to anthropogenic and natural forcing, part1: Wave climate variability and impacts on the longshore sediment transport. Continental Shelf Research 110, $48-59$. 
Almar, R., Larnier, S., Castelle, B., Scott, T., Floc'h, F., Detandt, G., 2015b. On the use of the radon transform to estimate longshore currents from video imagery. Coastal Engineering 114, 301-308.

Almar, R., Lerma, A.N., Castelle, B., Scott, T., 2018. On the influence of reflection over a rhythmic swash zone on surf zone dynamics. Ocean Dynamics , 1-11.

Ardhuin, F., Rascle, N., Belibassakis, K., 2008. Explicit wave-averaged primitive equations using a generalized lagrangian mean. Ocean Modelling 20, 35.

Auclair, F., Bordois, L., Dossmann, Y., Duhaut, T., Paci, A., Ulses, C., Nguyen, C., 2018. A non-hydrostatic non-boussinesq algorithm for free-surface ocean modelling. Ocean Modelling 132.

Barthelemy, E., 2004. Nonlinear shallow water theories for coastal waves. Surveys in Geophysics 25, 315-337.

Blaas, M., Dong, C., Marchesiello, P., McWilliams, J.C., Stolzenbach, K.D., 2007. Sediment-transport modeling on southern californian shelves: A ROMS case study. Continental Shelf Research 27, $832-853$.

Blayo, E., Debreu, L., 2005. Revisiting open boundary conditions from the point of view of characteristic variables. Ocean Modelling .

Bonneton, P., Bruneau, N., Castelle, B., Marche, F., 2010. Large scale vorticity generation due to dissipating waves in the surf zone. Discrete and Continuous Dynamical Systems - series B 13, 729-738.

Borges, R., Carmona, M., Costa, B., Don, W.S., 2008. An improved weighted essentially non-oscillatory scheme for hyperbolic conservation laws. Journal of Computational Physics 227, 3191 - 3211.

Bowen, A.J., Holman, R.A., 1989. Shear instabilities of the mean longshore current: 1. theory. Journal of Geophysical Research: Oceans 94, 18023-18030.

Burchard, H., Petersen, O., Rippeth, T.P., 1998. Comparing the performance of the mellor-yamada and the $k-\epsilon$ two-equation turbulence models. Journal of Geophysical Research: Oceans 103, 10543-10554.

Castelle, B., du Penhoat, Y., Almar, R., Anthony, E., Lefebvre, J.P., Laibi, R., Chuchla, R., Dorel, M., Senechal, N., 2014. Flash rip dynamics on a high-energy low-tide-terraced beach (grand popo, benin, west africa). Journal of Coastal Research 70, 633-638.

Chen, Q., Kirby, J.T., Dalrymple, R.A., Shi, F., Thornton, E.B., 2003. Boussinesq modeling of longshore currents. Journal of Geophysical Research: Oceans 108.

Cienfuegos, R., Barthélemy, E., Bonneton, P., 2010. Wave-breaking model for boussinesq-type equations including roller effects in the mass conservation equation. Journal of Waterway, Port, Coastal, and Ocean Engineering 136, 10-26.

Clark, D.B., Elgar, S., Raubenheimer, B., 2012. Vorticity generation by short-crested wave breaking. Geophysical Research Letters 39.

Cox, D.T., Anderson, S.L., 2001. Statistics of intermittent surf zone turbulence and observations of large eddies using piv. Coastal Engineering Journal 43, 121-131.

Cox, D.T., Kobayashi, N., Okayasu, A., 1994. Vertical Variations of Fluid Velocities and Shear Stress in 
Surf Zones. pp. 98-112.

Craik, A.D.D., 1971. Non-linear resonant instability in boundary layers. Journal of Fluid Mechanics 50, 393-413. doi $10.1017 /$ S0022112071002635.

Debreu, L., Marchesiello, P., Penven, P., Cambon, G., 2012. Two-way nesting in split-explicit ocean models: Algorithms, implementation and validation. Ocean Modelling 49-50, 1 - 21.

Derakhti, M., Kirby, J.T., 2014. Bubble entrainment and liquid-bubble interaction under unsteady breaking waves. Journal of Fluid Mechanics 761, 464-506.

Derakhti, M., Kirby, J.T., Shi, F., Ma, G., 2016. Nhwave: Consistent boundary conditions and turbulence modeling. Ocean Modelling 106, 121 - 130 .

Derian, P., Almar, R., 2017. Wavelet-based optical flow estimation of instant surface currents from shorebased and uav videos. IEEE Transactions on Geoscience and Remote Sensing 55, 5790-5797.

Devolder, B., Troch, P., Rauwoens, P., 2018. Performance of a buoyancy-modified $k-\omega$ and $k-\omega$ sst turbulence model for simulating wave breaking under regular waves using openfoam. Coastal Engineering $138,49-65$.

Dodd, N., Iranzo, V., Reniers, A., 2000. Shear instabilities of wave-driven alongshore currents. Reviews of Geophysics 38, 437-463.

Dodd, N., Oltman-Shay, J., Thornton, E.B., 1992. Shear instabilities in the longshore current: A comparison of observation and theory. Journal of Physical Oceanography 22, 62-82.

Elgar, S., Guza, R.T., 1985. Observations of bispectra of shoaling surface gravity waves. Journal of Fluid Mechanics 161, 425-448.

Elgar, S., Raubenheimer, B., 2020. Field Evidence of Inverse Energy Cascades in the Surfzone. Journal of Physical Oceanography 50, 2315-2321.

Feddersen, F., 2014. The generation of surfzone eddies in a strong alongshore current. Journal of Physical Oceanography 44, 600-617.

Feddersen, F., Clark, D.B., Guza, R.T., 2011. Modeling surf zone tracer plumes: 2. transport and dispersion. Journal of Geophysical Research: Oceans 116.

Feddersen, F., Trowbridge, J., 2005. The effect of wave breaking on surf-zone turbulence and alongshore currents: A modeling study. Journal of Physical Oceanography 35.

Floc'h, F., Mabiala, G., Almar, R., Castelle, B., Hall, N., Du Penhoat, Y., Scott, T., Delacourt, C., 2018. Flash rip statistics from video images. Journal of Coastal Research 81, 100-106.

Hally-Rosendahl, K., Feddersen, F., 2016. Modeling surfzone to inner-shelf tracer exchange. Journal of Geophysical Research: Oceans 121, 4007-4025.

Henderson, S., Arnold, J., Özkan Haller, H., Solovitz, S., 2017. Depth dependence of nearshore currents and eddies. Journal of Geophysical Research: Oceans 122. 
Herbert, T., 1983. Secondary instability of plane channel flow to subharmonic three-dimensional disturbances. The Physics of Fluids 26, 871-874.

Herman, A., Dojczman, M., Swiszcz, K., 2020. High-resolution simulations of interactions between surface ocean dynamics and frazil ice. The Cryosphere 14, 3707-3729.

Hilt, M., Auclair, F., Benshila, R., Bordois, L., Capet, X., Debreu, L., Dumas, F., Jullien, S., Lemarié, F., Marchesiello, P., Nguyen, C., Roblou, L., 2020. Numerical modelling of hydraulic control, solitary waves and primary instabilities in the strait of gibraltar. Ocean Modelling 151, 101642.

Johnson, D., Pattiaratchi, C., 2006. Boussinesq modelling of transient rip currents. Coastal Engineering 53, $419-439$.

Kazakova, M., Richard, G.L., 2019. A new model of shoaling and breaking waves: one-dimensional solitary wave on a mild sloping beach. Journal of Fluid Mechanics 862, 552-591.

Kirby, J.T., 2016. Boussinesq models and their application to coastal processes across a wide range of scales. Journal of Waterway, Port, Coastal, and Ocean Engineering 142, 03116005.

Kirby, J.T., Derakhti, M., 2019. Short-crested wave breaking. European Journal of Mechanics - B/Fluids $73,100-111$.

Kumar, N., Feddersen, F., 2017. The effect of stokes drift and transient rip currents on the inner shelf. part i: No stratification. Journal of Physical Oceanography 47, 227-241.

Kumar, N., Voulgaris, G., Warner, J.C., Olabarrieta, M., 2012. Implementation of the vortex force formalism in the coupled ocean-atmosphere-wave-sediment transport (coawst) modeling system for inner shelf and surf zone applications. Ocean Modelling 47, 65 - 95 .

Lannes, D., Bonneton, P., 2009. Derivation of asymptotic two-dimensional time-dependent equations for surface water wave propagation. Physics of Fluids 21, 016601.

Larsen, B.E., Fuhrman, D.R., 2018. On the over-production of turbulence beneath surface waves in reynoldsaveraged navier-stokes models. Journal of Fluid Mechanics 853, 419-460.

Larsen, B.E., van der A, D.A., van der Zanden, J., Ruessink, G., Fuhrman, D.R., 2020. Stabilized rans simulation of surf zone kinematics and boundary layer processes beneath large-scale plunging waves over a breaker bar. Ocean Modelling 155, 101705.

Larson, M., , Kraus, N., 2002. NMLONG: Numerical model for simulating longshore current; Report 2: Wave-current interaction, roller modeling, and validation of model enhancements. Technical Report. Technical Report ERDC/CHL TR-02- 22, US Army Engineer Research and Development Center, Vicksburg, MS

Lesieur, M., 1990. Turbulence in Fluids. Fluid Mechanics and its Applications, Springer Netherlands.

Li, L., Dalrymple, R.A., 1998. Instabilities of the undertow. Journal of Fluid Mechanics 369, 175-190. doi $10.1017 / \mathrm{S} 0022112098001694$ 
Lin, P., Li, C.W., 2002. A $\sigma$-coordinate three-dimensional numerical model for surface wave propagation. International Journal for Numerical Methods in Fluids 38, 1045-1068.

Lin, P., Liu, P.L.F., 1998. A numerical study of breaking waves in the surf zone. Journal of Fluid Mechanics $359,239-264$.

Lippmann, T.C., Thornton, E.B., Stanton, T.P., 2016. The Vertical Structure of Low-Frequency Motions in the Nearshore. Part I: Observations. Journal of Physical Oceanography 46, 3695-3711.

Longo, S., Petti, M., Losada, I.J., 2002. Turbulence in the swash and surf zones: a review. Coastal Engineering 45, 129 - 147. Surface and Swash Zone Mechanics.

Lubin, P., Chanson, H., 2017. Are breaking waves, bores, surges and jumps the same flow? Environmental Fluid Mechanics 17, 47-77.

Lubin, P., Glockner, S., 2015. Numerical simulations of three-dimensional plunging breaking waves: generation and evolution of aerated vortex filaments. Journal of Fluid Mechanics 767, 364-393.

Ma, G., Shi, F., Kirby, J.T., 2012. Shock-capturing non-hydrostatic model for fully dispersive surface wave processes. Ocean Modelling 43-44, 22 - 35.

MacMahan, J.H., Thornton, E.B., Reniers, A.J., 2006. Rip current review. Coastal Engineering 53, 191 208. Coastal Hydrodynamics and Morphodynamics Symposium celebrating the academic closing address of Jurjen A. Battjes.

Marchesiello, P., Benshila, R., Almar, R., Uchiyama, Y., McWilliams, J.C., Shchepetkin, A., 2015. On tridimensional rip current modeling. Ocean Modelling 96, 36 - 48. Waves and coastal, regional and global processes.

Marchesiello, P., Capet, X., Menkes, C., Kennan, S.C., 2011. Submesoscale dynamics in tropical instability waves. Ocean Modelling 39, 31-46.

Marchesiello, P., McWilliams, J.C., Shchepetkin, A., 2001. Open boundary conditions for long-term integration of regional oceanic models. Ocean modelling 3, 1-20.

Mayer, S., Madsen, P.A., 2000. Simulation of Breaking Waves in the Surf Zone using a Navier-Stokes Solver. pp. 928-941.

McWilliams, J.C., Akan, C., Uchiyama, Y., 2018. Robustness of nearshore vortices. Journal of Fluid Mechanics 850, R2.

McWilliams, J.C., Restrepo, J.M., Lane, E.M., 2004. An asymptotic theory for the interaction of waves and currents in coastal waters. Journal of Fluid Mechanics 511, 135-178.

Menesguen, C., Le Gentil, S., Marchesiello, P., Ducousso, N., 2018. Destabilization of an oceanic meddy-like vortex: energy transfers and significance of numerical settings. Journal Of Physical Oceanography 48, $1151-1168$.

Metcalfe, R.W., Orszag, S.A., Brachet, M.E., Menon, S., Riley, J.J., 1987. Secondary instability of a 
temporally growing mixing layer. Journal of Fluid Mechanics 184, 207-243.

Michalke, A., 1964. On the inviscid instability of the hyperbolictangent velocity profile. Journal of Fluid Mechanics 19, 543-556.

Michalke, A., 1965. On spatially growing disturbances in an inviscid shear layer. Journal of Fluid Mechanics $23,521-544$.

Michallet, H., Ruessink, B.G., Vieira Lima Matias da Rocha, M., De Bakker, A., Van Der A, D.A., Ruju, A., Silva, P.A., Sénéchal, N., Marieu, V., Tissier, M., Almar, R., Abreu, T., Birrien, F., Vignal, L., Barthélemy, E., Mouazé, D., Cienfuegos, R., Wellens, P., 2014. GLOBEX: Wave dynamics on a shallow sloping beach, in: HYDRALAB IV Joint User Meeting, Lisbon, July 2014, Lisbonne, Portugal. pp. 1-12. Mocke, G.P., 2001. Structure and modeling of surf zone turbulence due to wave breaking. Journal of Geophysical Research: Oceans 106, 17039-17057.

Nadaoka, K., Hino, M., Koyano, Y., 1989. Structure of the turbulent flow field under breaking waves in the surf zone. Journal of Fluid Mechanics 204, 359-387.

Newberger, P.A., Allen, J.S., 2007. Forcing a three-dimensional, hydrostatic, primitive-equation model for application in the surf zone: 2. application to duck94. Journal of Geophysical Research: Oceans 112.

Noyes, T.J., Guza, R.T., Feddersen, F., Elgar, S., Herbers, T.H.C., 2005. Model-data comparisons of shear waves in the nearshore. Journal of Geophysical Research: Oceans 110.

Özkan-Haller, H.T., Kirby, J.T., 1999. Nonlinear evolution of shear instabilities of the longshore current: A comparison of observations and computations. Journal of Geophysical Research: Oceans 104, 2595325984.

Penney, J., Morel, Y., Haynes, P., Auclair, F., Nguyen, C., 2020. Diapycnal mixing of passive tracers by kelvin-helmholtz instabilities. Journal of Fluid Mechanics 900, A26.

Peregrine, D.H., 1998. Surf zone currents. Theor. Comput. Fluid Dyn. 10, 295-309.

Pierrehumbert, R., Widnall, S., 1982. The two- and three-dimensional instabilities of a spatially periodic shear layer. Journal of Fluid Mechanics 114, 59 - 82.

Roelvink, J.A., Reniers, 1995. IP 11D delta flume experiments : a dataset for profile model validation. WL / Delft Hydraulics.

de Schipper, M.A., Reniers, A.J., Ranasinghe, R., Stive, M.J., 2014. The influence of sea state on formation speed of alongshore variability in surf zone sand bars. Coastal Engineering 91, $45-59$.

Scott, T., Castelle, B., Almar, R., Senechal, N., Floch, F., Detandt, G., 2018. Controls on flash rip current hazard on low-tide terraced tropical beaches in west africa. Journal of Coastal Research 81, 92-99.

Shchepetkin, A.F., McWilliams, J.C., 2005. The regional oceanic modeling system (roms): a split-explicit, free-surface, topography-following-coordinate oceanic model. Ocean Modelling 9, 347-404.

Shi, F., Kirby, J.T., Harris, J.C., Geiman, J.D., Grilli, S.T., 2012. A high-order adaptive time-stepping tvd 
solver for boussinesq modeling of breaking waves and coastal inundation. Ocean Modelling 43-44, 36 51

Short, A.D., Hogan, C.L., Safety, A.B., Program., M., 1993. Beaches of the New South Wales coast : a guide to their nature, characteristics, surf and safety. Australian Beach Safety and Management Program Beaconsfield, N.S.W.

Slinn, D.N., Allen, J.S., Newberger, P.A., Holman, R.A., 1998. Nonlinear shear instabilities of alongshore currents over barred beaches. Journal of Geophysical Research 103, 18,357 - 18,379.

Soufflet, Y., Marchesiello, P., Lemarié, F., Jouanno, J., Capet, X., Debreu, L., Benshila, R., 2016. On effective resolution in ocean models. Ocean Modelling 98, 36-50.

Splinter, K.D., Slinn, D.N., 2003. Three-dimensional modeling of alongshore current dynamics, in: Canadian Coastal Conference, Kingston, Ontario, pp. 1-14.

Spydell, M., Feddersen, F., 2009. Lagrangian drifter dispersion in the surf zone: Directionally spread, normally incident waves. Journal of Physical Oceanography 39, 809-830.

Svendsen, I., 1987. Analysis of surf zone turbulence. Journal of Geophysical Research: Oceans 92, 5115-5124.

Svendsen, I.A., Madsen, P.A., 1984. A turbulent bore on a beach. Journal of Fluid Mechanics 148, 73-96.

Tissier, M., Bonneton, P., Marche, F., Chazel, F., Lannes, D., 2012. A new approach to handle wave breaking in fully non-linear boussinesq models. Coastal Engineering 67, 54-66.

Uchiyama, Y., McWilliams, J., Shchepetkin, A., 2010. Wave-current interaction in an oceanic circulation model with a vortex-force formalism: Application to the surf zone. Ocean Modelling 34, 16-35.

Uchiyama, Y., McWilliams, J.C., Akan, C., 2017. Three-dimensional transient rip currents: Bathymetric excitation of low-frequency intrinsic variability. Journal of Geophysical Research: Oceans 122, 5826-5849.

Uchiyama, Y., McWilliams, J.C., Restrepo, J.M., 2009. Wave-current interaction in nearshore shear instability analyzed with a vortex force formalism. Journal of Geophysical Research: Oceans 114.

Warner, J., Sherwood, C., Arango, H., Signell, R., 2005. Performance of four turbulence closure methods implemented using a generic length scale method. Ocean Modelling 8, 81-113.

Warner, J.C., Defne, Z., Haas, K., Arango, H.G., 2013. A wetting and drying scheme for ROMS. Computers and Geosciences 58, 54-61.

Warner, J.C., Sherwood, C.R., Signell, R.P., Harris, C.K., Arango, H.G., 2008. Development of a threedimensional, regional, coupled wave, current, and sediment-transport model. Computers \& Geosciences $34,1284-1306$

Watanabe, Y., Saeki, H., 1999. Three-dimensional large eddy simulation of breaking waves. Coastal Engineering Journal 41, 281-301.

Watanabe, Y., Saeki, H., Hosking, R.J., 2005. Three-dimensional vortex structures under breaking waves. Journal of Fluid Mechanics 545, 291-328. 
Wei, G., Kirby, J.T., Sinha, A., 1999. Generation of waves in boussinesq models using a source function method. Coastal Engineering 36, 271 - 299.

1087 Wilcox, D.C., 1988. Reassessment of the scale-determining equation for advanced turbulence models. AIAA 1088 Journal 26, 1299-1310.

1089 Zijlema, M., Stelling, G., Smit, P., 2011. Swash: An operational public domain code for simulating wave fields and rapidly varied flows in coastal waters. Coastal Engineering 58, $992-1012$. 
Table 1: Model setup of CROCO's Grand Popo Beach configuration

\begin{tabular}{|c|c|}
\hline Model parameters & Values \\
\hline Grid type & $\begin{array}{l}\text { Horizontal: rectangular structured; verti- } \\
\text { cal: free-surface, terrain-following }\end{array}$ \\
\hline Domain size $\left(L_{x}, L_{y}\right)$ & $240 \times 542 \mathrm{~m}$ \\
\hline Horizontal resolution (dx/dy) & $0.5 \mathrm{~m}$ \\
\hline Vertical grid $(\mathrm{Nz})$ & 10 levels $(\mathrm{dz}=10 \mathrm{~cm}$ over the terrace) \\
\hline Time step & $\begin{array}{l}\mathrm{dt}=0.01 \quad \mathrm{~s}, \quad \mathrm{c}_{\text {sound }}=200 \mathrm{~m} / \mathrm{s} \quad \text { (pseudo- } \\
\text { acoustic) }\end{array}$ \\
\hline Bathymetry (h) & $\begin{array}{l}\text { longshore-uniform low tide terrace derived } \\
\text { from March } 2014 \text { survey }\end{array}$ \\
\hline Tides & mid-tide: 1 -m depth over the terrace \\
\hline Wave forcing ( $\mathrm{u}, \mathrm{v}, \mathrm{w}$ at offshore boundary) & $\begin{array}{l}\text { linear wave solutions reconstructed from } \\
\text { JONSWAP spectrum with } H_{s}=1.15 \mathrm{~m} \\
\text { and } T_{p}=11 \mathrm{~s}\end{array}$ \\
\hline Air-sea fluxes $(\mathrm{u}, \mathrm{v}, \mathrm{T}, \mathrm{S})$ & No \\
\hline Sediment model $\left(\mathrm{D} 50, w_{s}, E_{0}, \tau_{c r}\right)$ & $\begin{array}{l}D 50=100 \mu \mathrm{m} ; w_{s}=5 \mathrm{~mm} / \mathrm{s} ; E_{0}=10^{-5} \\
\mathrm{~kg} / \mathrm{m}^{2} / \mathrm{s} ; \tau_{c r}=0.01 \mathrm{~N} / \mathrm{m}^{2}\end{array}$ \\
\hline Breaking/turbulence & $\begin{array}{l}\text { WENO5-Z shock-capturing advection } \\
\text { scheme } \\
k-\omega(\text { or } k-\epsilon) \text { turbulence model }\end{array}$ \\
\hline Bottom roughness $\left(z_{0}\right)$ & $0.01-1 \mathrm{~mm}$ \\
\hline
\end{tabular}


Table 2: List of CROCO simulations for Grand Popo Beach.

\begin{tabular}{c|ccc|c}
\hline Simulation & Breaking & Wave type & Direction & Test \\
\hline \hline 3D_SC_D10 & shallow & short-crested & $10^{\circ}$ & Data vs. 3D instab. \\
2D_SC_D10 & deep & short-crested & $10^{\circ}$ & vs. Peregrine process \\
\hline 3D_SC_D0 & shallow & short-crested & $0^{\circ}$ & 3D instab. vs. \\
2D_SC_D0 & deep & short-crested & $0^{\circ}$ & Peregrine process \\
3D_LC_D0 & shallow & long-crested & $0^{\circ}$ & \\
3D_MONO_D0 & shallow & monochromatic & $0^{\circ}$ & \\
\hline 3D_LC_D10 & shallow & long-crested & $10^{\circ}$ & 3D instab. vs. 2DH \\
2D_LC_D10 & deep & long-crested & $10^{\circ}$ & instab. \\
\hline FUNWAVE-TVD & deep & short-crested & $0^{\circ}$ & Test of pseudo-2D CROCO \\
\hline
\end{tabular}



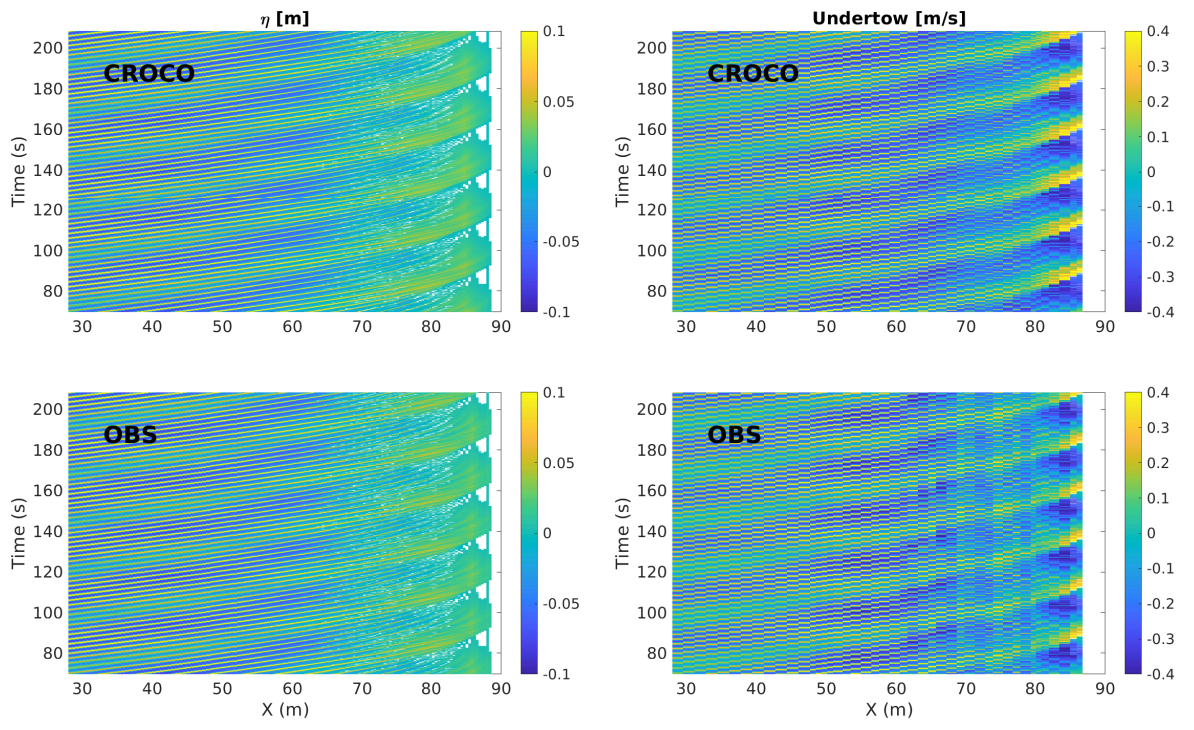

Figure 1: Hovmuller plot (x,time) of data and model sea level $\eta$ and undertow $u_{b}$ for the GLOBEX B3 flume experiment. When data is missing in the measurements, it is also removed from the model output. 


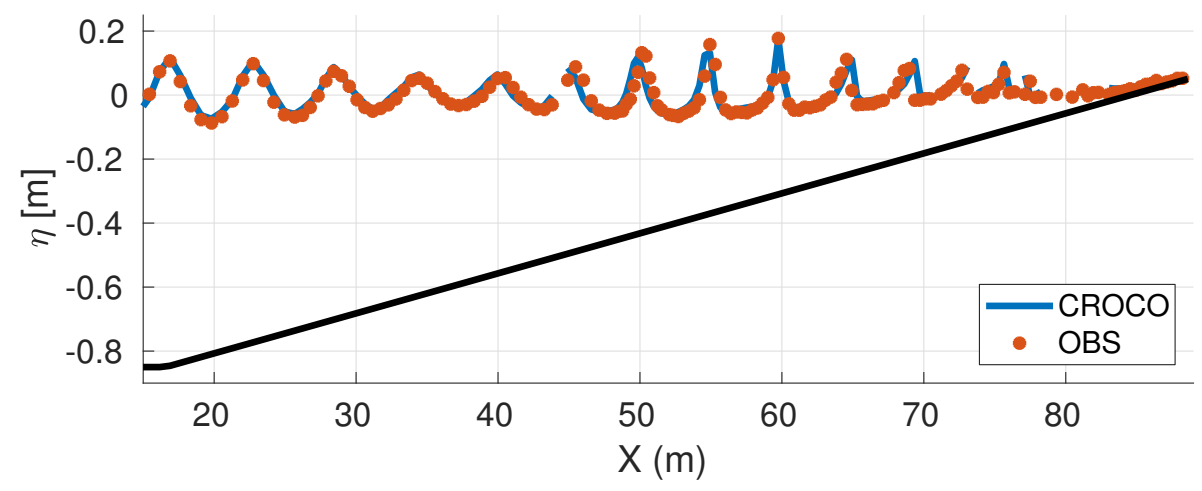

Figure 2: Snapshot of wave field across the GLOBEX B3 flume experiment during runup conditions for model (blue line) and data (red dots). 

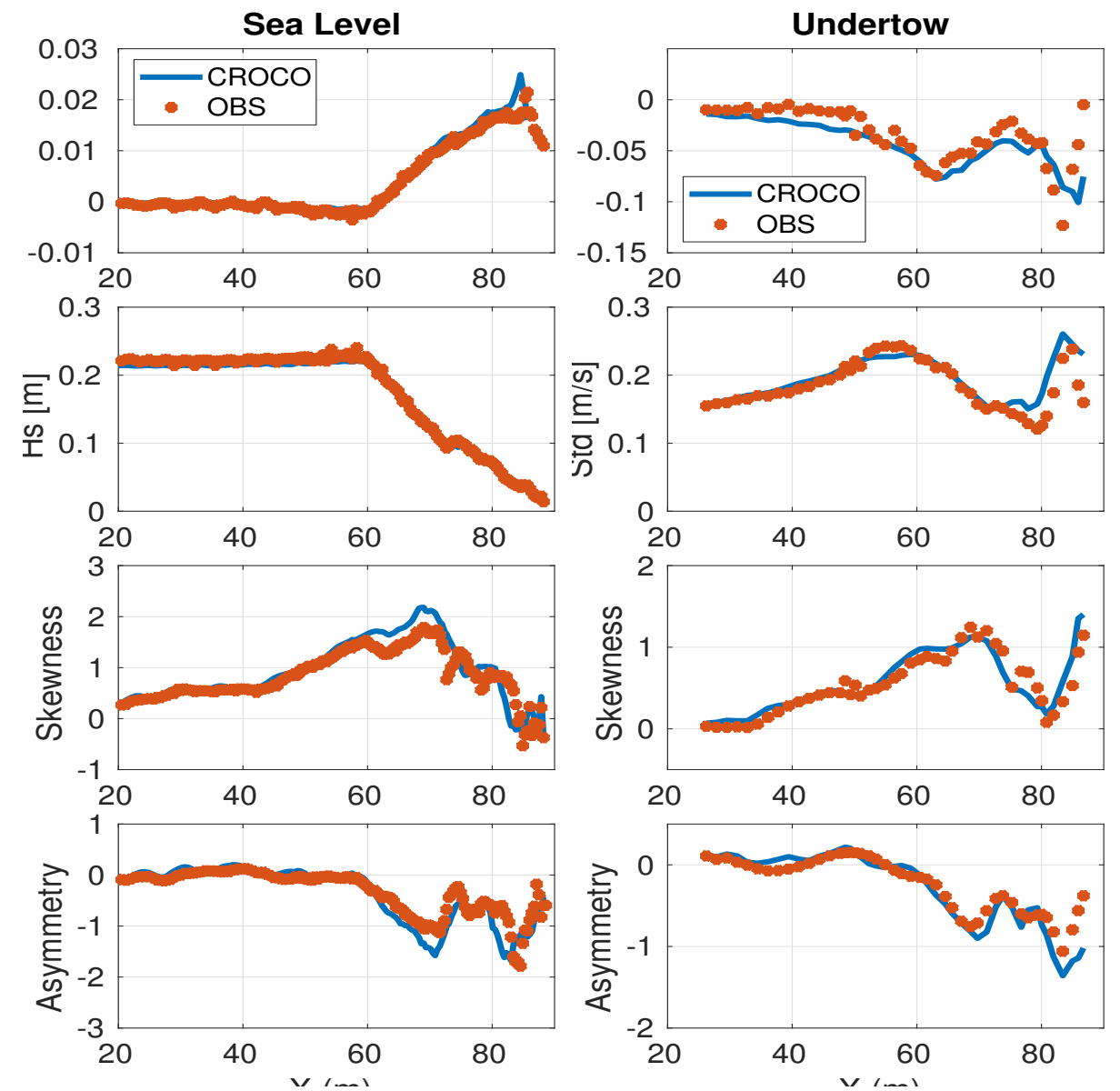

Figure 3: Wave statistics from GLOBEX B3 experiment for sea level $\eta$ (right) and undertow $u_{b}$ (left) in the model (blue line) and data (red line or dots). From top to bottom: mean, standard deviation (or $H_{s}$ for $\eta$ ), skewness and asymmetry. 

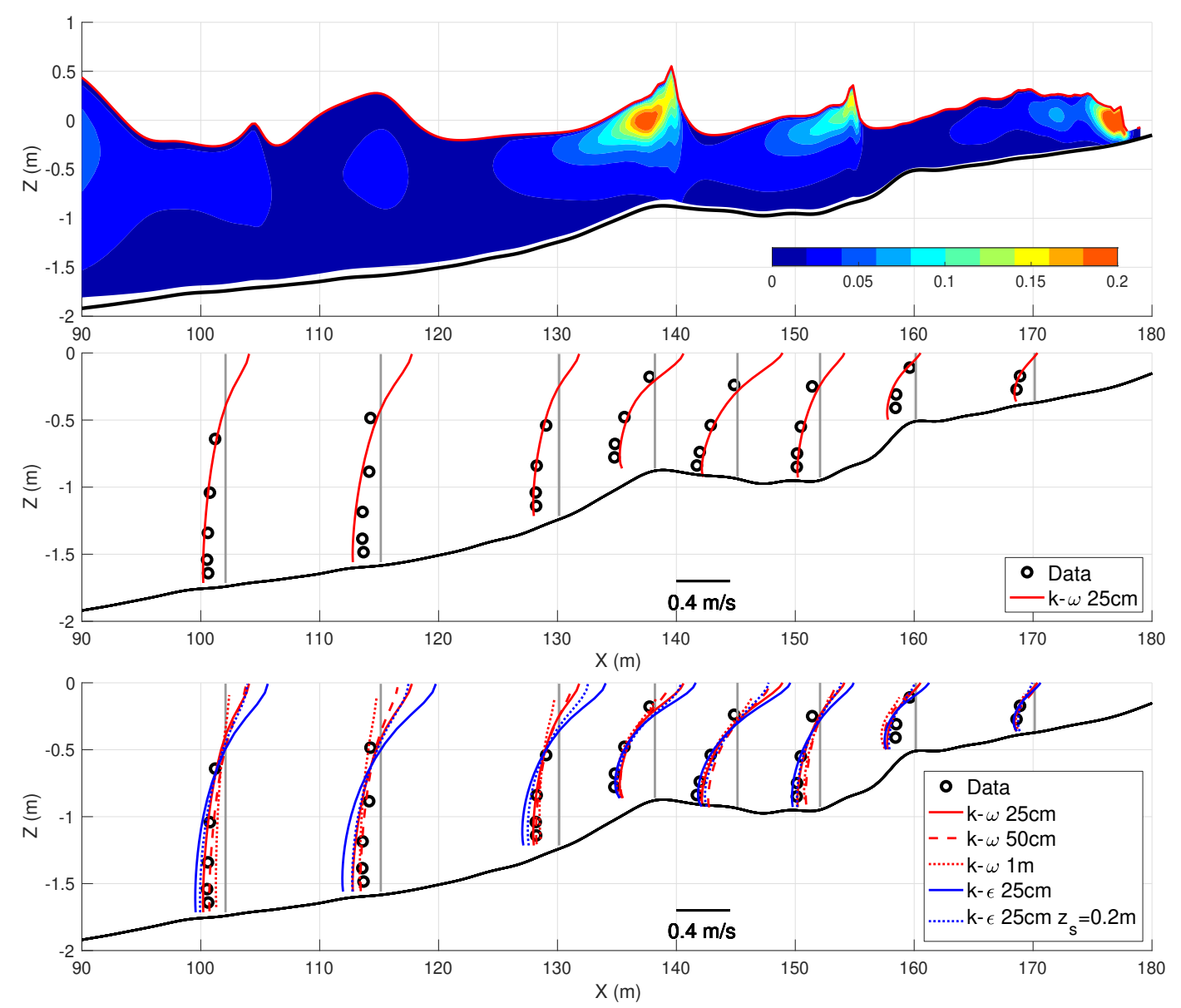

Figure 4: Model comparison with the large-scale LIP11-1B Flume experiment. Top) Snapshot of wave height and turbulent kinetic energy $k$ from the reference model simulation $(25 \mathrm{~cm}$ resolution; $k-\omega$ turbulence model). Middle) Comparison of simulated and measured current profiles. Bottom) Sensitivity to resolutions $(25 \mathrm{~cm}, 50 \mathrm{~cm}$ and $1 \mathrm{~m})$ and turbulence models $(k-\omega$ in red; $k-\epsilon$ in blue). 


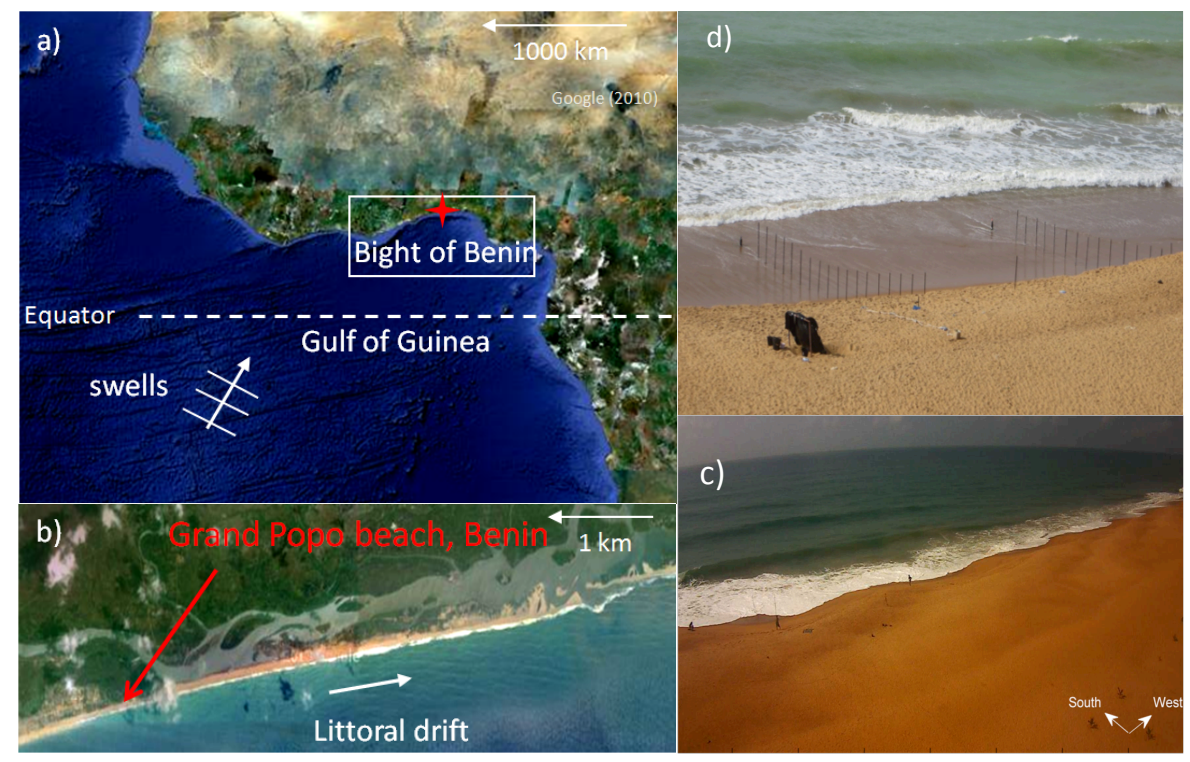

Figure 5: Grand Popo Beach $\left(6.2^{\circ} \mathrm{N}, 1.7^{\circ} \mathrm{E}\right)$ is a longshore uniform beach located off Benin in the Gulf of Guinea (a-b-c). It is representative of an open, wave-dominated and microtidal environment exposed to S-SW long period swells generated at high latitudes in the South Atlantic. Panel (d) shows Grand Popo's low-tide terrace where instruments were deployed in March 2014 (the terrace is exposed here during low tide). 


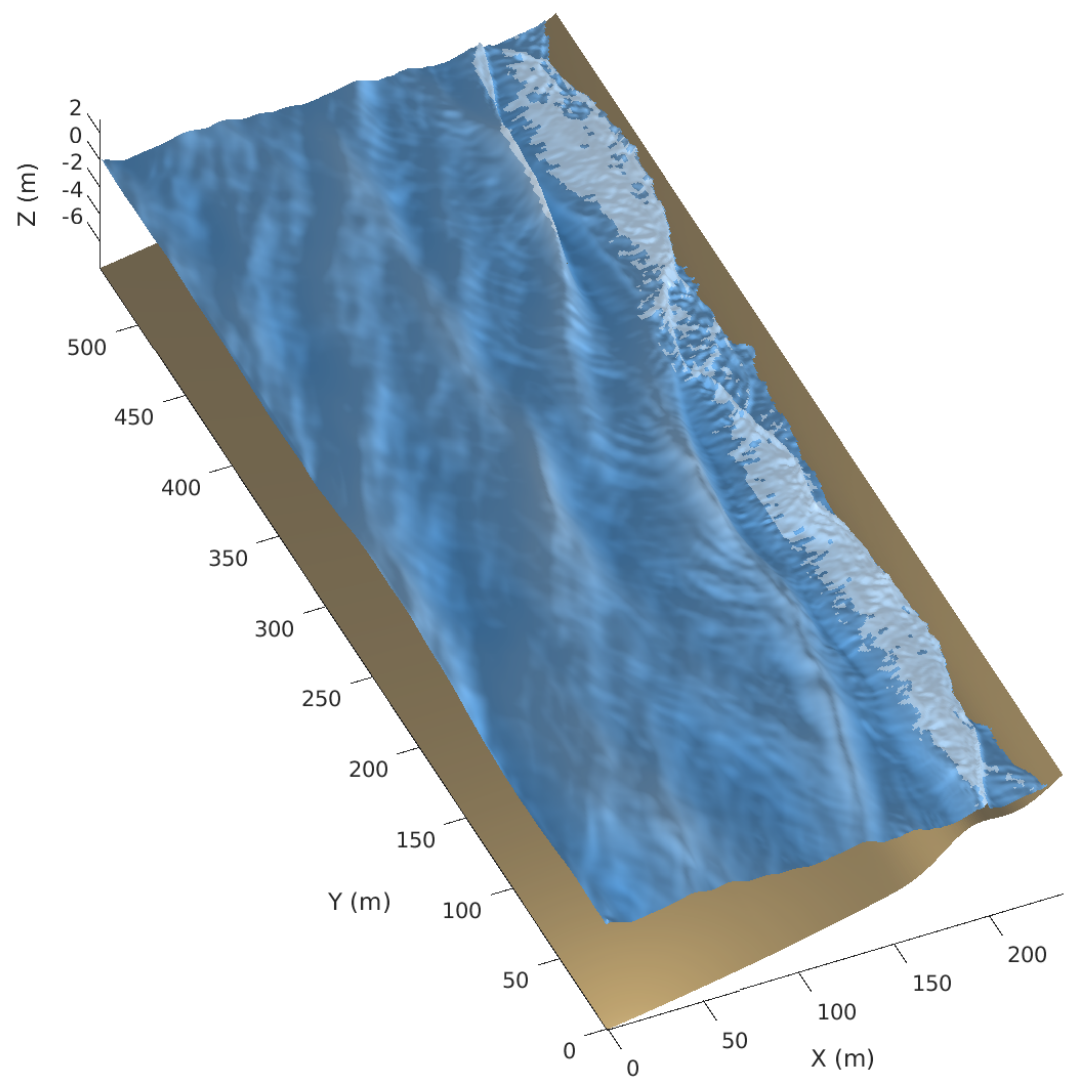

Figure 6: 3D representation of surface waves in CROCO. Short-crested waves are generated at the offshore boundary and propagate shoreward at an angle of $10^{\circ}$, with refraction and breaking through the surf and swash zones. Foam in the surfzone is approximated by white patches in locations of high turbulent kinetic energy of the subgrid-scale model. 

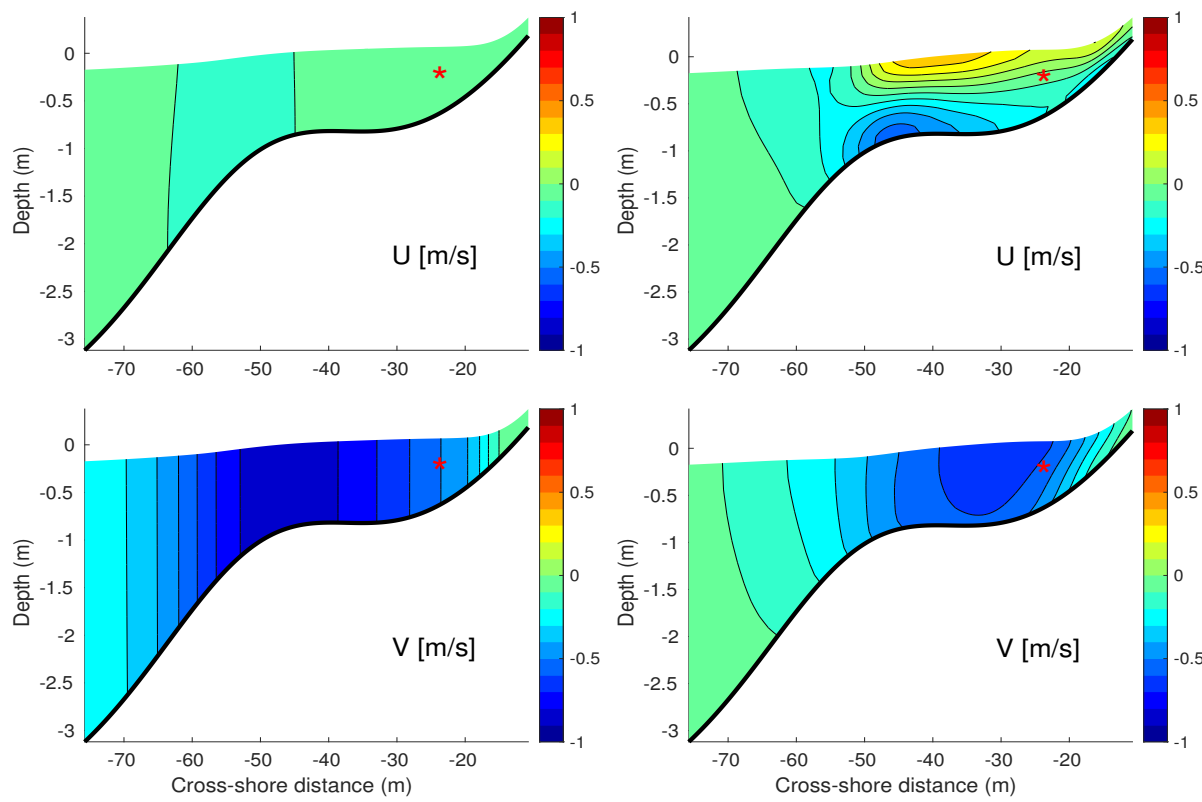

Figure 7: Cross-section of time-mean and longshore-mean, cross-shore (top) and longshore (bottom) currents in the case of shallow (right) and deep (left) breaking. The location of ADV measurement is indicated by a red star.

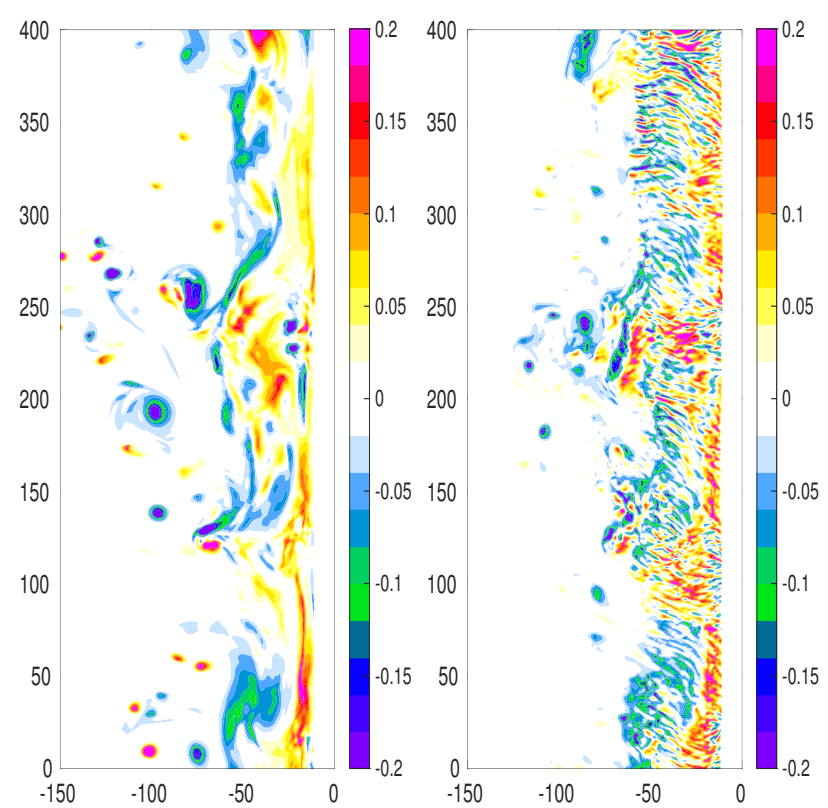

Figure 8: Surface vertical vorticity snapshot in the case of shallow (right) and deep (left) breaking. 

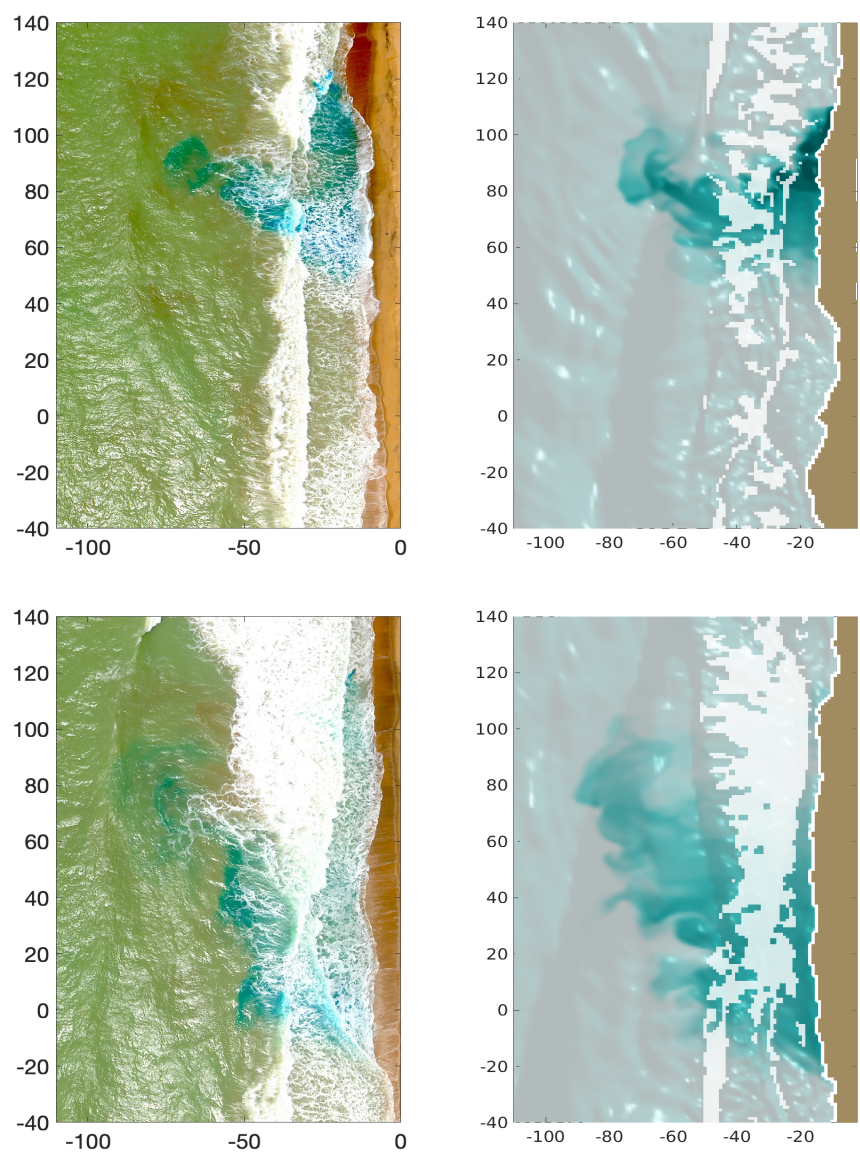

Figure 9: Drone photos (left) and CROCO simulation (right) of dye release at $116 \mathrm{~s}$ interval during the Grand Popo survey of March 132014 at afternoon mid-tide. In the model, wave surfaces are presented in the background with light from the left (as in the photos), and foam is approximated by high turbulent energy levels as in Fig. 6] 


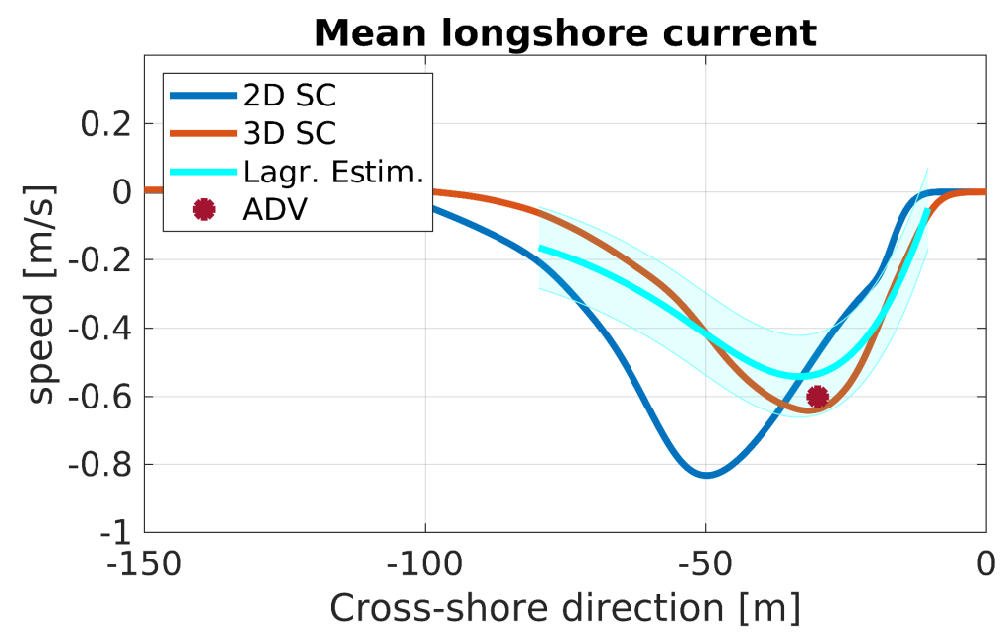

Figure 10: Cross-shore profile of time-mean and longshore-mean surface longshore flow for the full 3D simulation with wave direction $D=10^{\circ}$. ADV measurement (extrapolated to the surface using the model profiles) and an estimation of Lagrangian velocities from drone photos (Fig. 9) is added for comparison.
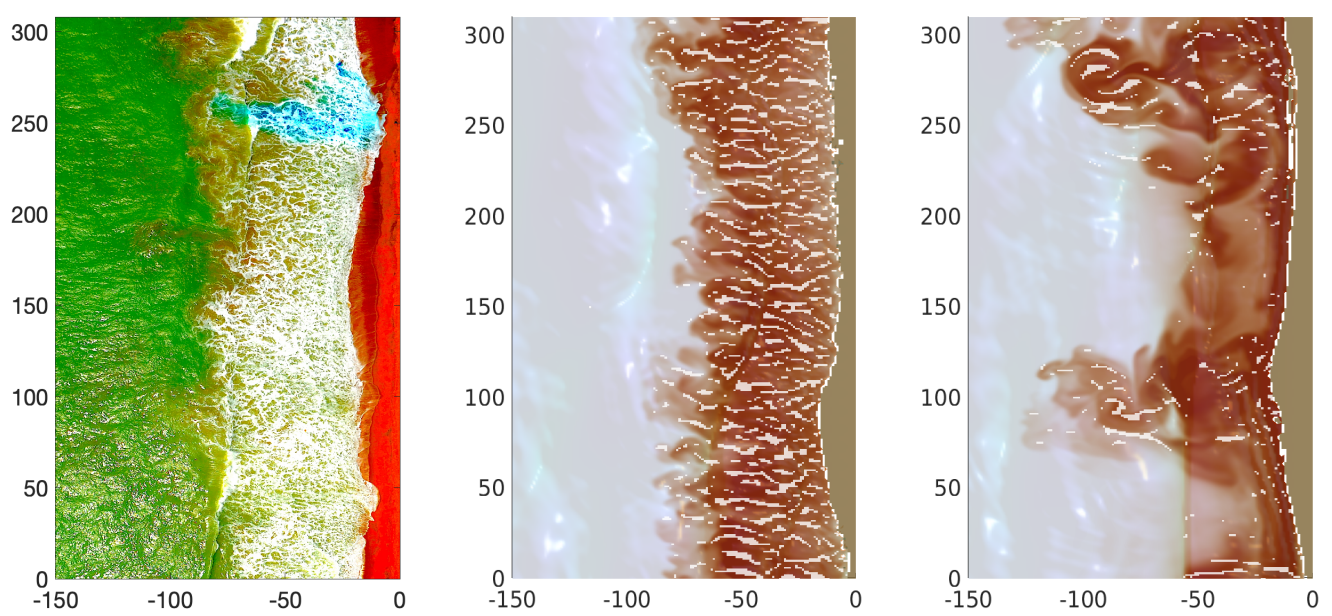

Figure 11: Aerial photo (left) and CROCO simulations of surfzone suspended sediments for shallow-breaking (center) and deep-breaking (right) cases. The contrasts in the photo is enhanced to better expose suspended sediments (brown color). The model suspended sediments correspond to snapshots at 15 min of simulation. Lines of strong alongshore convergence of surface currents are represented with white patches, to compare with foam structures observed in the photo. 

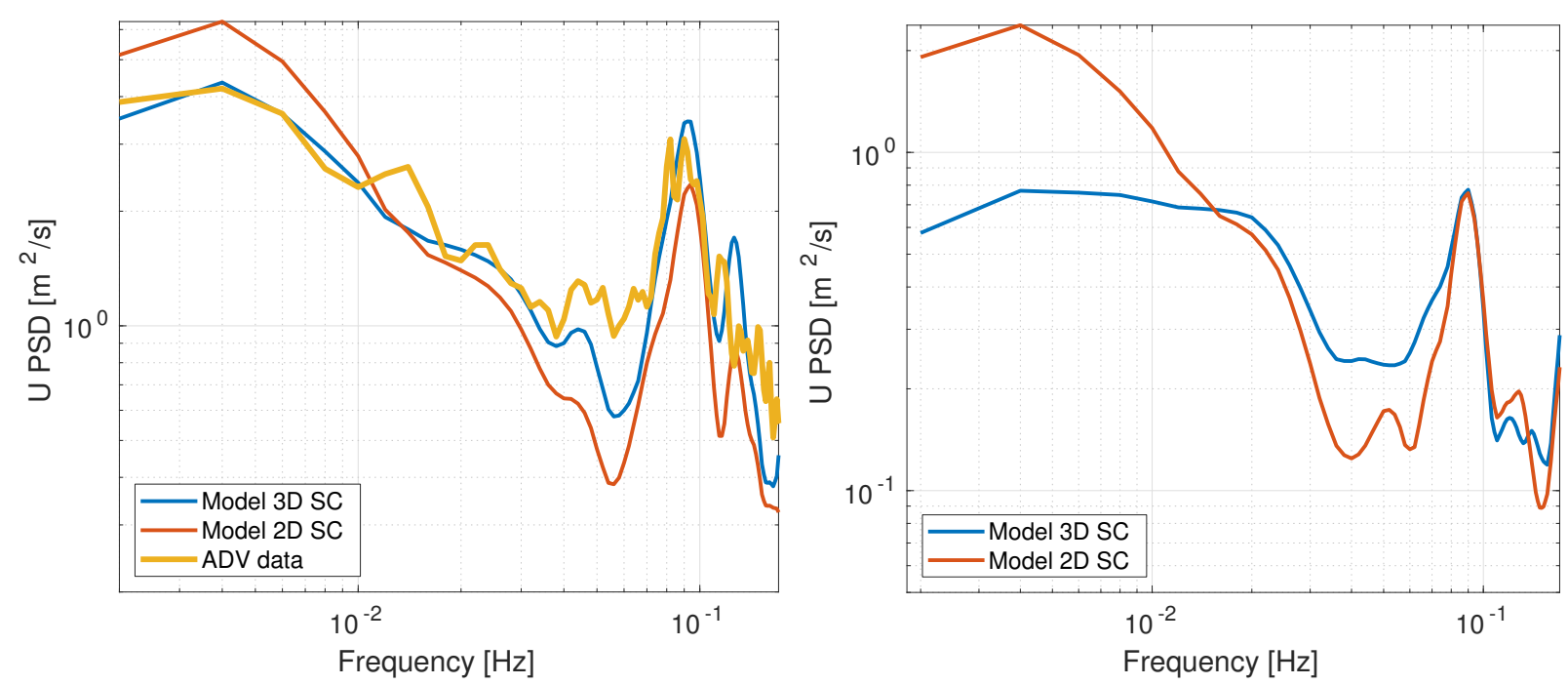

Figure 12: Power Spectral Density of horizontal velocity fluctuations compared with ADV measurements in the middle of the terrace (left) and over the outer terrace slope (right), in March 132014 at afternoon mid-tide. 


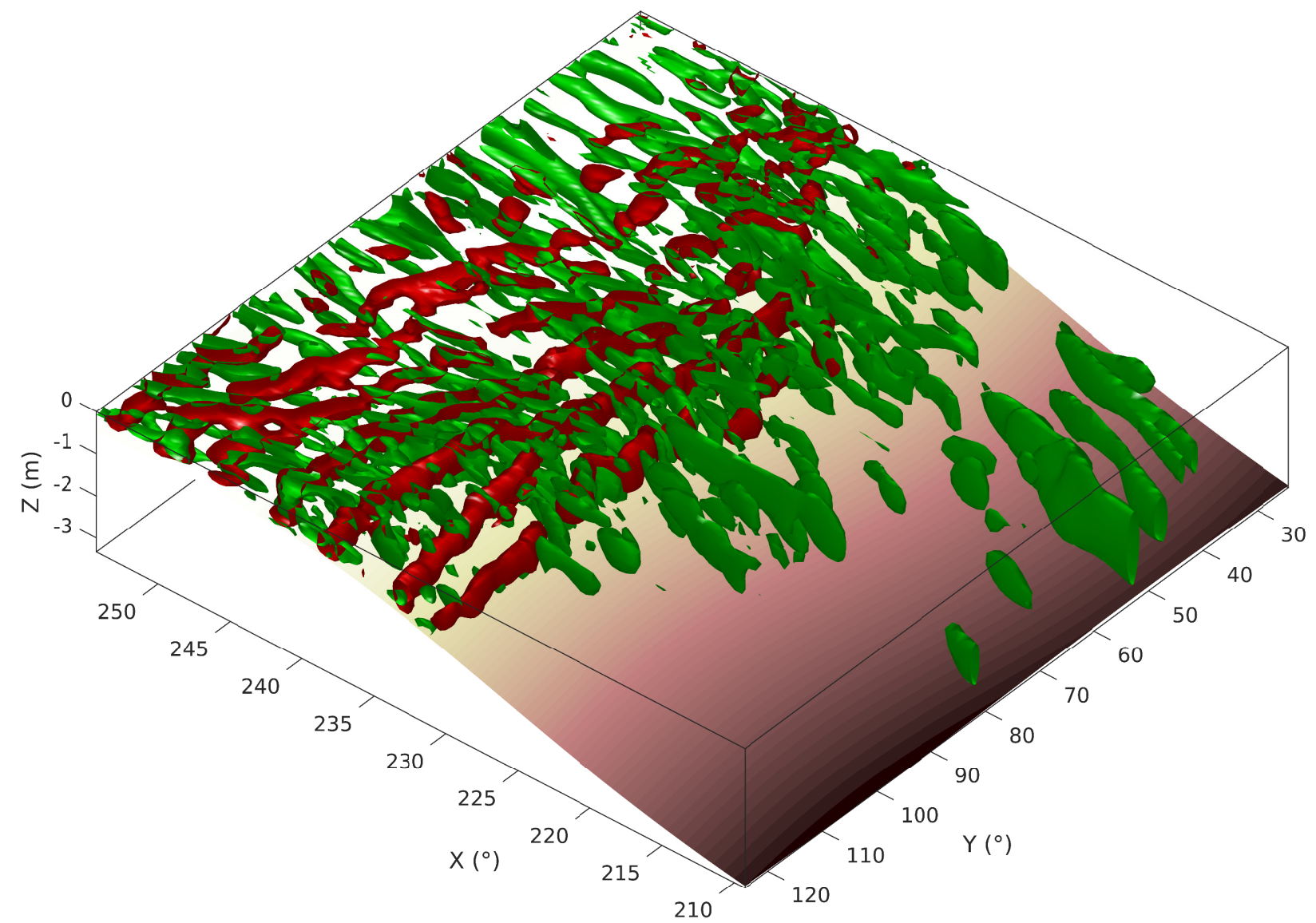

Figure 13: Q field defined by $Q=-\frac{1}{2} \frac{\partial u_{i}}{\partial x_{j}} \frac{\partial u_{j}}{\partial x_{i}}$, showing coherent structures similar to rolls and ribs in a transitional mixing layer. Cross-shore and alongshore Q terms are split: spanwise rolls (aligned across shear direction) are identified by $Q_{y}=-\frac{\partial u}{\partial z} \frac{\partial w}{\partial x}-\frac{1}{2} \frac{\partial u^{2}}{\partial x}$ in red; and streamwise ribs (along shear direction) are identified by $Q_{x}=-\frac{\partial v}{\partial z} \frac{\partial w}{\partial y}-\frac{1}{2} \frac{\partial v^{2}}{\partial y}$ in green. The fields are normalized and only positive isosurface values (0.02) are plotted. 


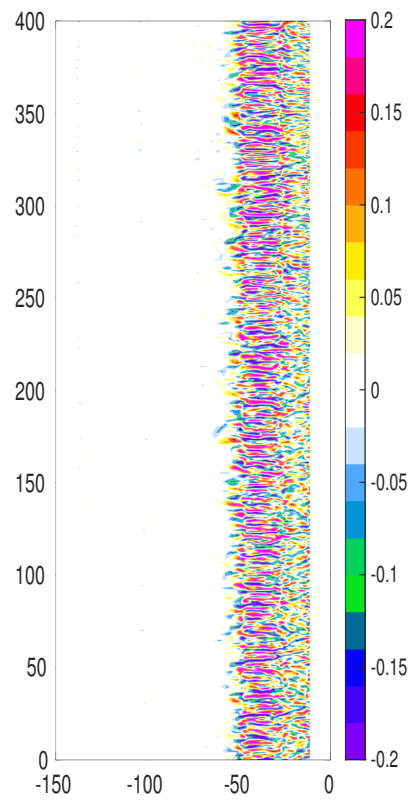

Figure 14: Surface vertical vorticity snapshot for the case with monochromatic shore-normal wave forcing (3D_MONO_D0) 

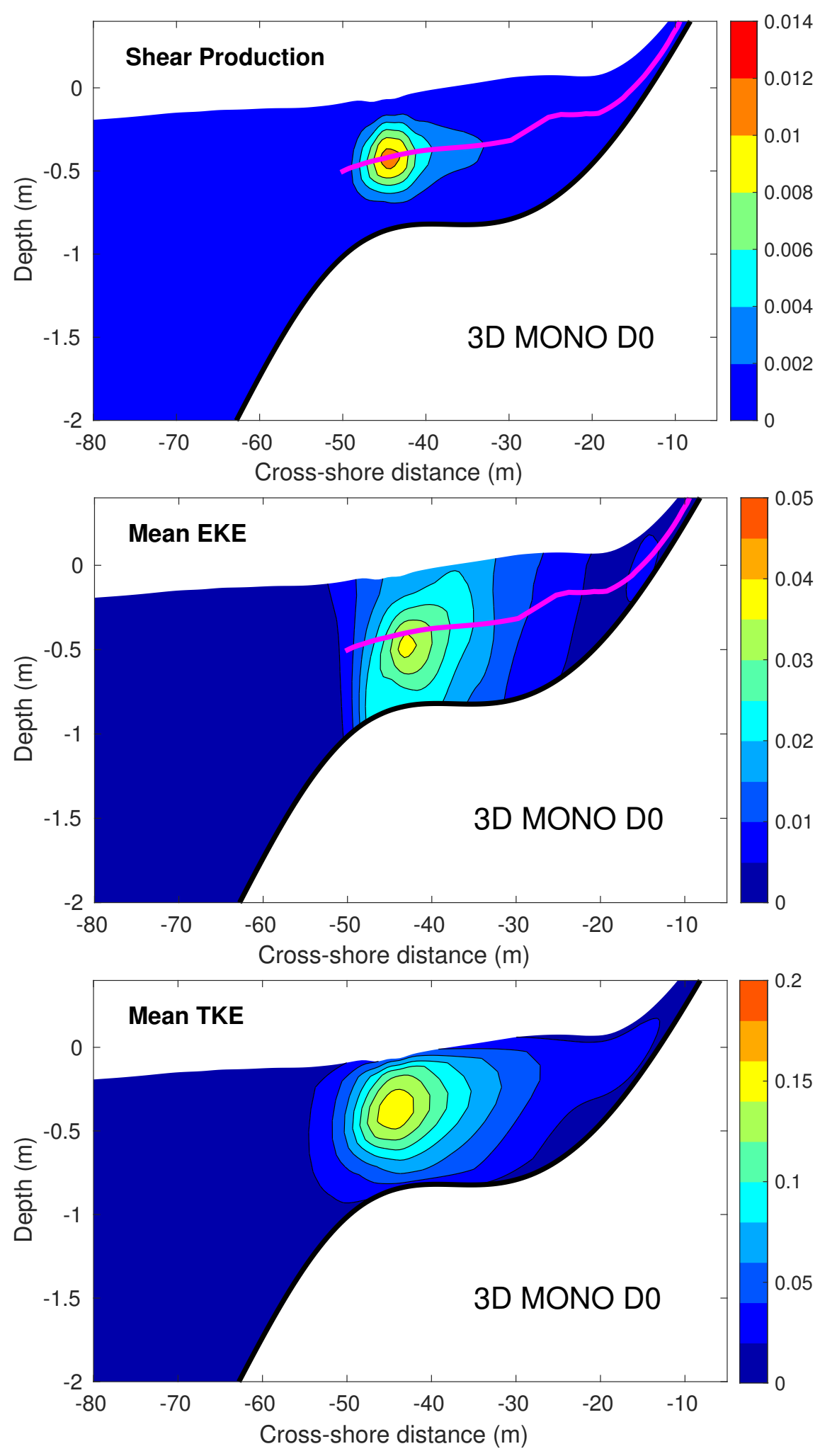

Figure 15: Cross-section of EKE production by the mean vertical shear flow $-\overline{u^{\prime} w^{\prime}} \frac{\partial \bar{u}}{\partial z}\left[\mathrm{~m}^{2} / \mathrm{s}^{3}\right]$ (top); Mean EKE $\left[\mathrm{m}^{2} / \mathrm{s}^{2}\right]$ (middle); Mean turbulent kinetic energy $\left.57 \mathrm{~m}^{2} / \mathrm{s}^{2}\right]$ given by the $k$ - $\omega$ model (bottom). All fields are for the case with 3D instabilities only, forced by monochromatic long-crested waves (3D_MONO_D0). The presence of an inflection point in the velocity profile where $\frac{\partial^{2} \bar{u}}{\partial z^{2}}=0$ is shown in a magenta line 


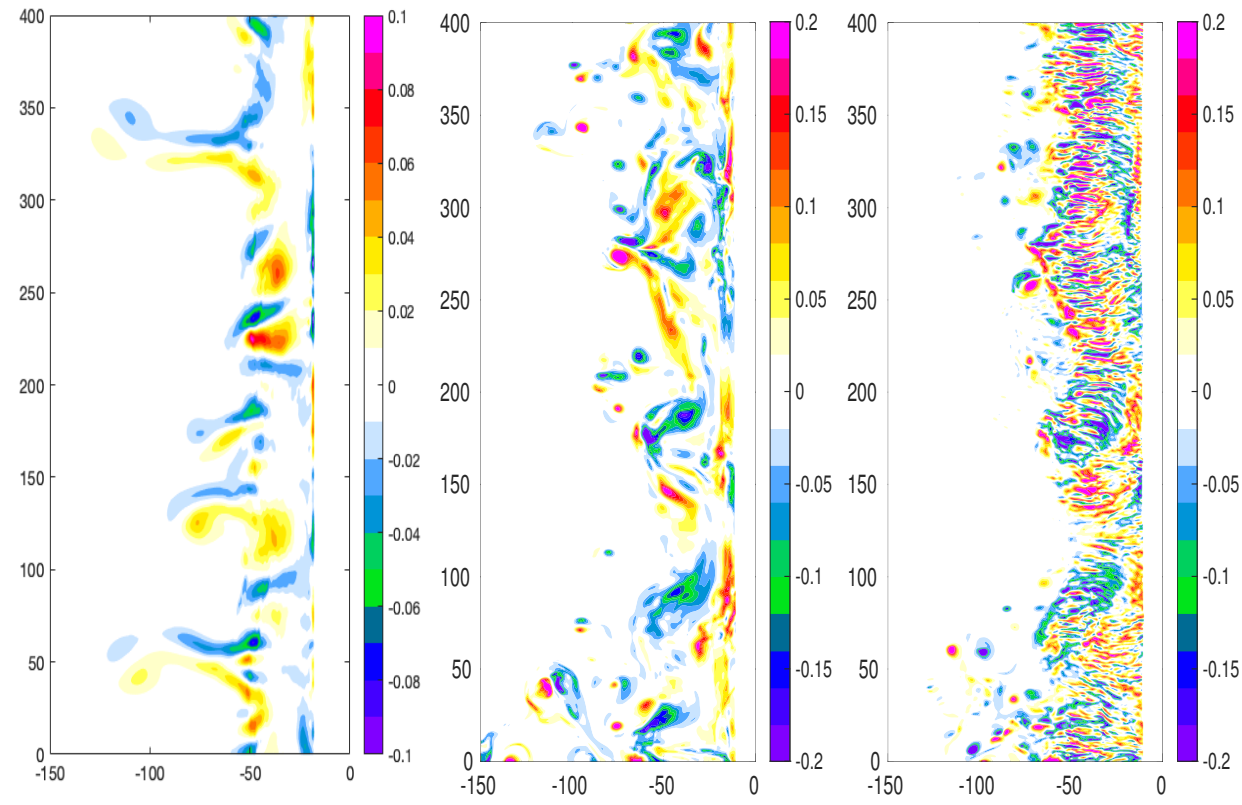

Figure 16: Vertical vorticity snapshot for 3 cases with shore-normal wave forcing: FUNWAVE-TVD (2D Boussinesq) with short-crested waves (left); CROCO with short-crested waves and deep breaking (center); short-crested waves and shallow breaking (right). 

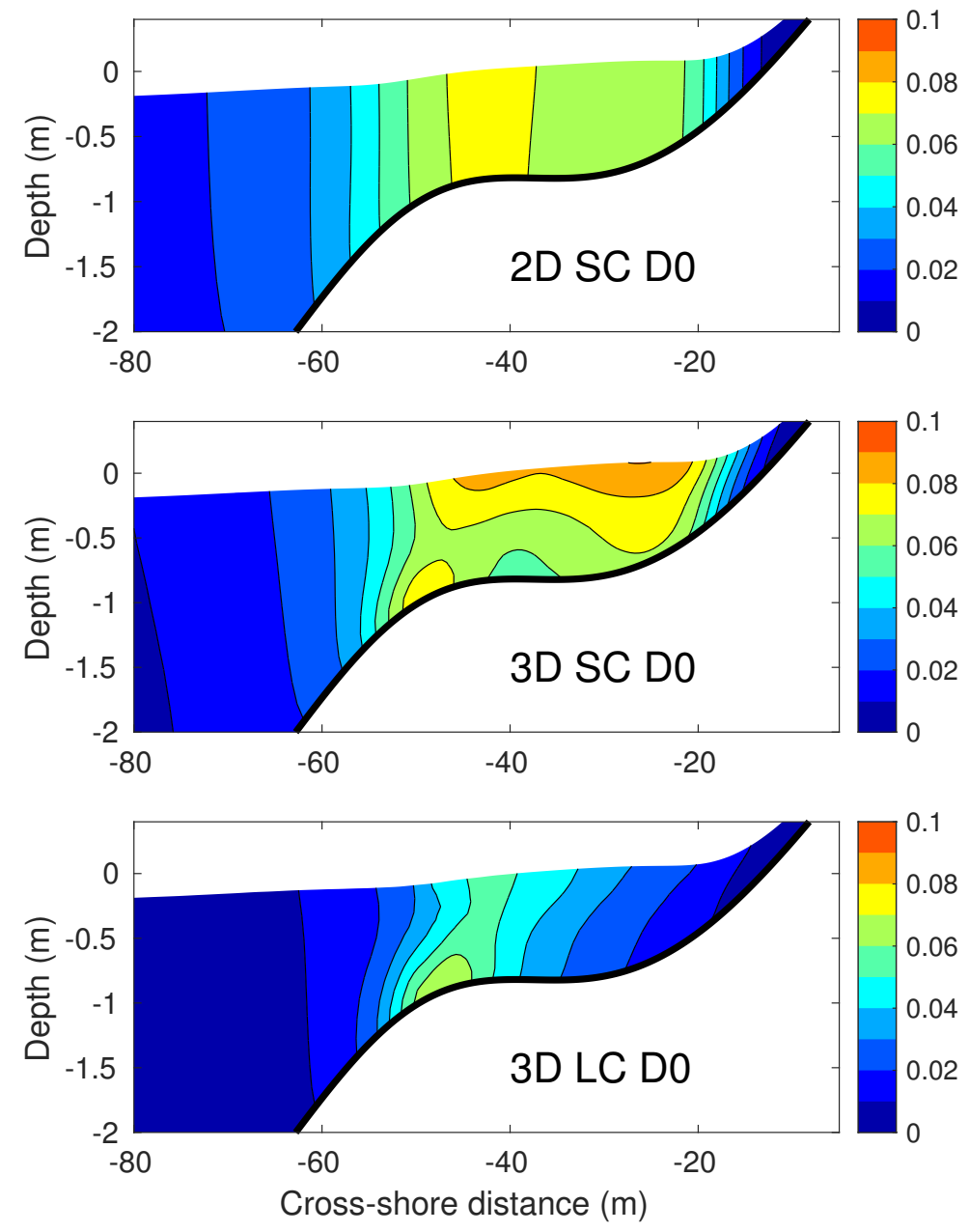

Figure 17: Cross-section of time-mean and longshore-mean EKE for the 3 cases of Figure 16 

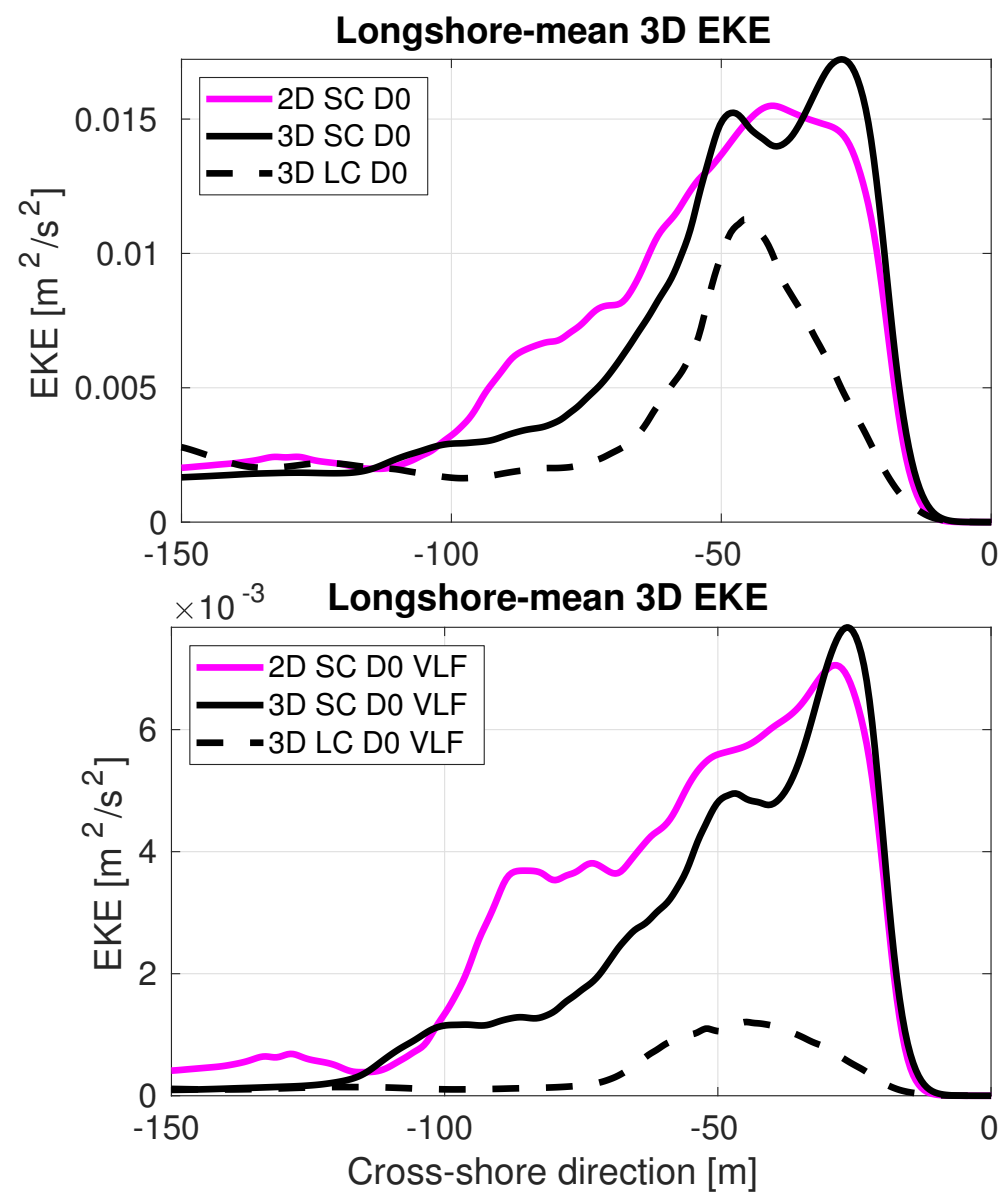

Figure 18: Cross-shore profile of depth-integrated (normalized), time and longshore-mean EKE for the 3 cases in Figure 16. Top: EKE of wave-averaged flow; bottom: EKE of low-pass filtered flow to remove 3D instability modes. 


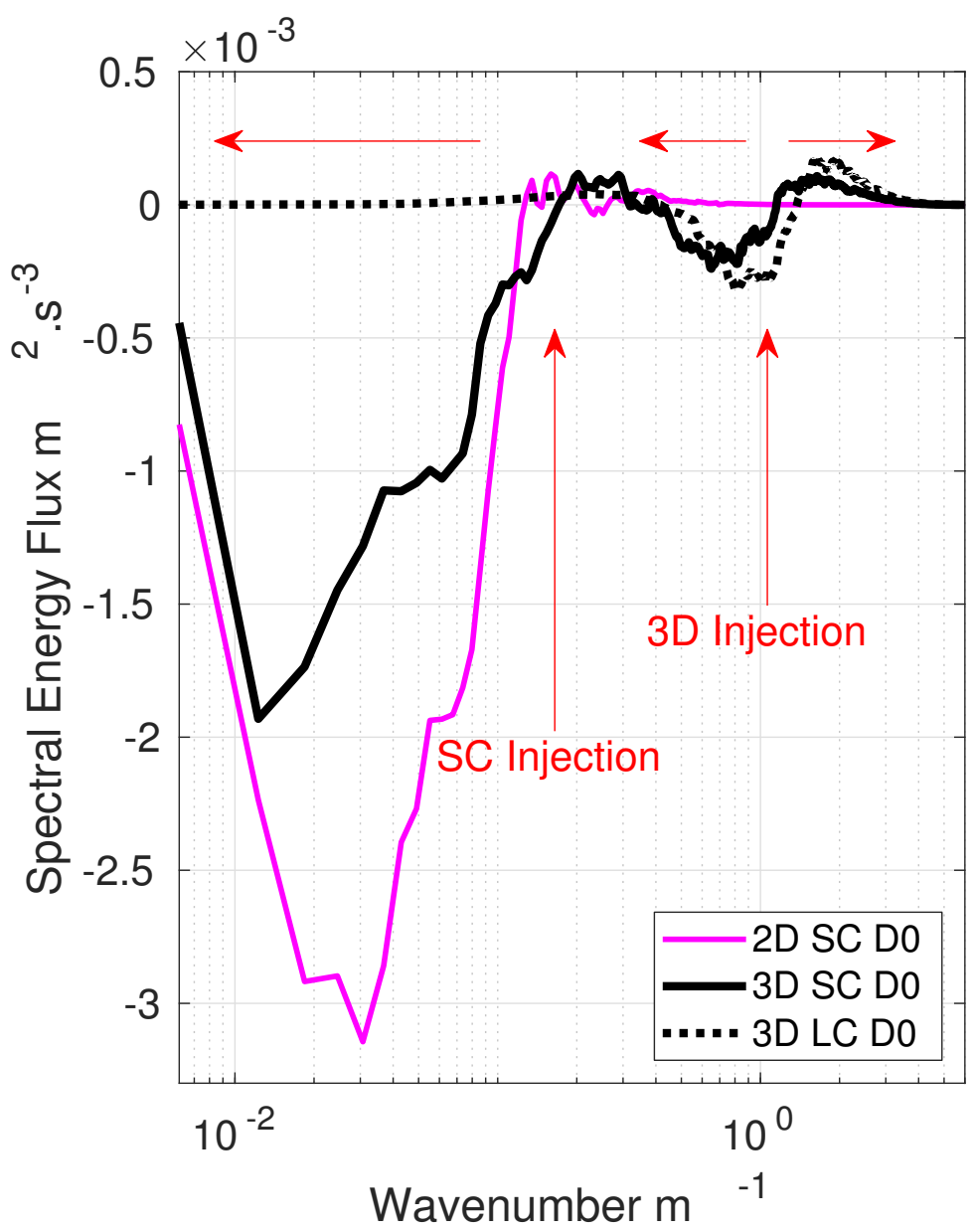

Figure 19: 3D and 2D model wavenumber spectral flux in the surfzone. Vertical red arrows point to the wavenumbers of energy injection from short-crested waves ( $30 \mathrm{~m}$ wavelength) and from 3D shear instability $(\sim 5 \mathrm{~m})$. The spectral flux is computed by spectral integration of $v$ advection term (Marchesiello et al. 2011). Horizontal red arrows indicate positive/negative fluxes, i.e., direct/inverse energy cascade toward smaller/larger scales. 


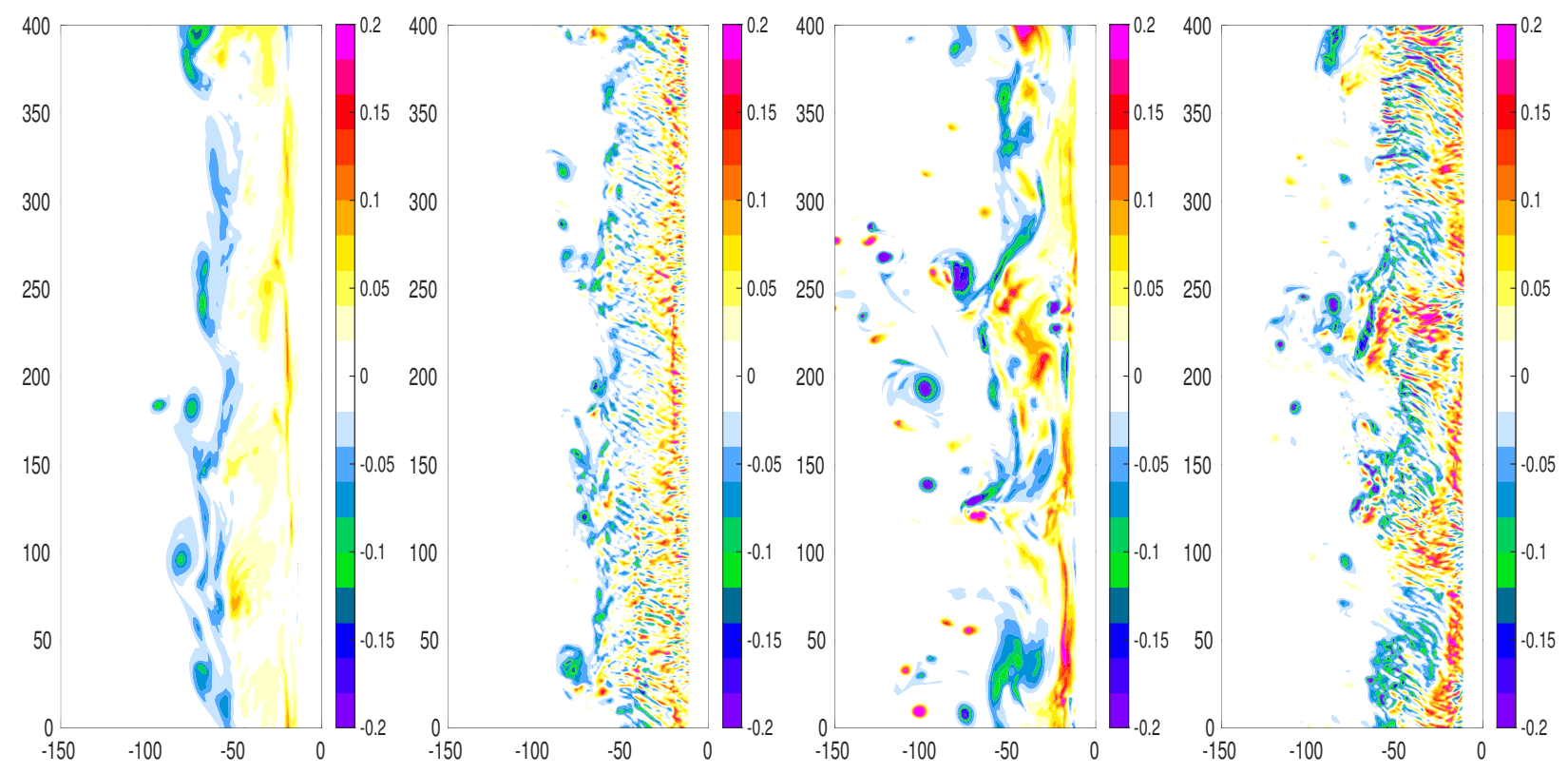

Figure 20: Snapshot of vorticity fields for 4 cases with oblique waves: long-crested waves with deep breaking (2D_LC_D10: first left); long-crested waves with shallow breaking (3D_LC_D10: second left); shortcrested waves with deep breaking (2D_SC_D10: second right); and short-crested waves with shallow breaking (3D_SC_D10: last right). 

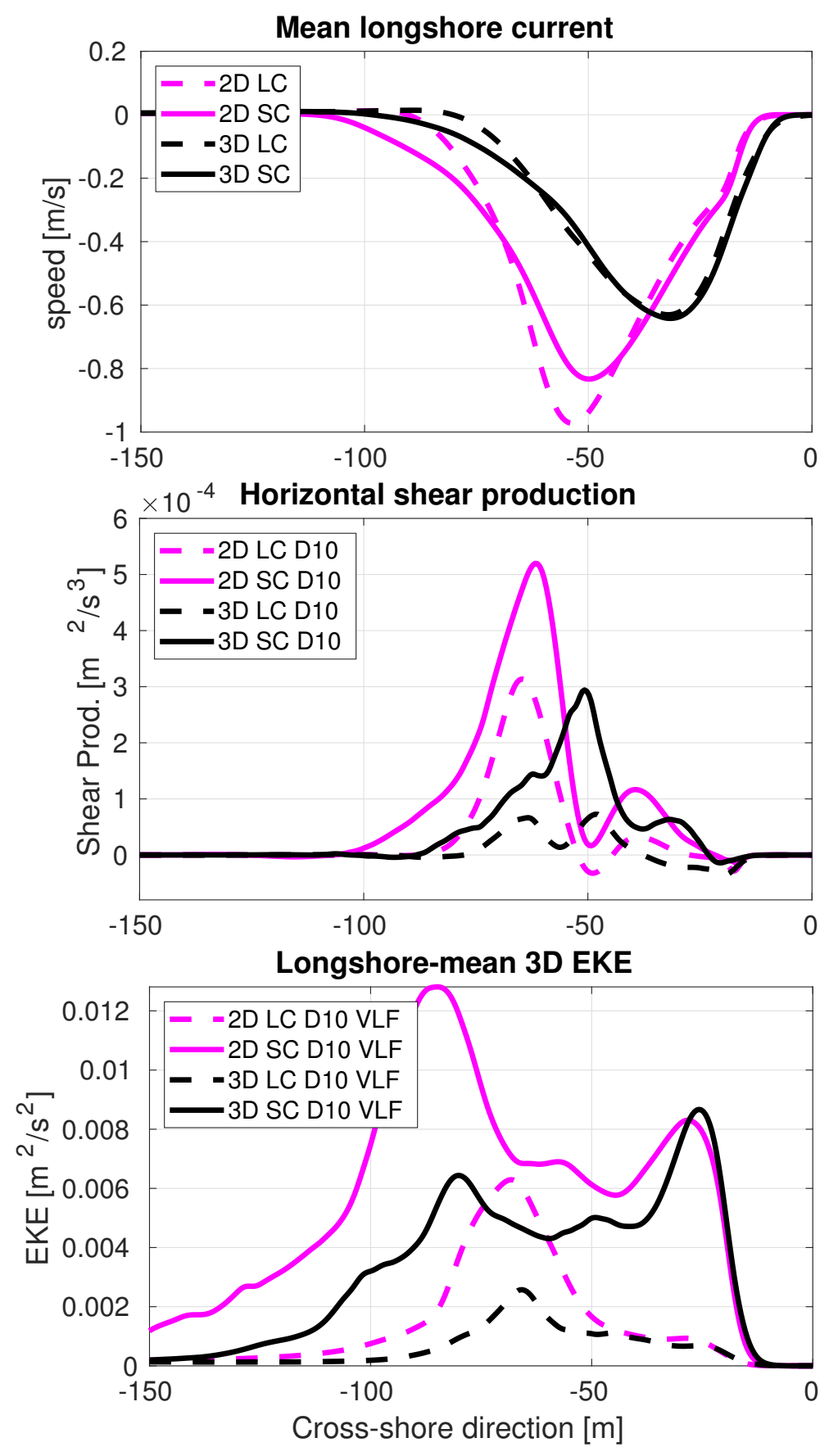

Figure 21: Cross-shore profile of time-mean and longshore-mean flow and eddy statistics for the 4 cases in Figure 16 top: surface longshore flow; center: horizontal shear production $-\overline{u^{\prime} v^{\prime}} \frac{\partial \bar{v}}{\partial x}$; bottom: depthintegrated EKE of low-frequency modes. 